\title{
Refinery Approach of Bio-oils Derived from Fast Pyrolysis of Lignin to Jet Fuel Range Hydrocarbons: Reaction Network Development for Catalytic Conversion of Cyclohexanone
}

\author{
Majid Saidi ${ }^{1}$, Alireza Jahangiri \\ Faculty of Engineering and Technology, Shahrekord University, Shahrekord, Iran
}

\begin{abstract}
This study demonstrated that the bio-oil derived from fast pyrolysis of lignin was excellent candidate to be converted into the jet and diesel fuel range hydrocarbons by catalytic upgrading process. This research addresses specifically the kinetic and mechanism of cyclohexanone conversion using sulfided $\mathrm{CoMo} / \gamma-\mathrm{Al}_{2} \mathrm{O}_{3}$ catalyst in a fixed-bed flow reactor. The main routes of cyclohexanone upgrading included hydrodeoxygenations (HDO), dehydrogenation, hydrogenation and coupling. The selectivity-conversion analyses at different operating condition indicate that benzene, cyclohexene, phenol, and 2-cyclohexen-1-one formed as primary products and the other main products, 2-methylphenol, cyclohexylbenzene, biphenyl, 2-phenylphenol, 2-cyclohexylcyclohexan-1-one, 2-cyclohexylidenecyclohexane-1-one and 2-cyclohexylphenol appeared as non-primary products. An approximate reaction network and a first order kinetic model are developed to determine kinetic parameters. Kinetic investigations indicate that among the various reactions on sulfided $\mathrm{CoMo} / \mathrm{Al}_{2} \mathrm{O}_{3}, \mathrm{HDO}$ is characterized by the highest rate and that selectivities for oxygen removal are favored by operation at higher temperatures and pressures. The apparent activation energy for the HDO reaction that leads to benzene formation is approximately $35.6 \mathrm{~kJ} / \mathrm{mol}$; coupling is the reaction class characterized by the
\end{abstract}

\footnotetext{
${ }^{1}$ Corresponding Author: Majid Saidi, m.saidi@eng.sku.ac.ir, majidsaidi65@gmail.com
} 
highest apparent activation energy. The pseudo-first-order rate constants for formation of the main products of cyclohexanone conversion decrease in the following order: benzene > 2-cyclohexylidenecyclohexane-1-one > cyclohexylbenzene > 2-cyclohexen-1-one > 2-phenylphenol > phenol > cyclohexene > 2-cyclohexylphenol > 2-methylphenol > 2-cyclohexylcyclohexan-1-one > biphenyl.

Keywords: Bio-oil; Lignin; Cyclohexanone; Catalytic Upgrading; Hydrodeoxygenation.

\section{Introduction}

In recent years, due to increasing demand for diesel and jet fuel and growing awareness of important environmental issues, there is an immense interest in developing new generation hydrocarbon biofuels, with a particular focus on green aviation biofuels (Alonso et al., 2010; Czernik and Bridgwater, 2004; Hosseinzadeh et al., 2015; Naik et al., 2014; Rahimpour et al., 2016; Saidi et al., 2016; Saidi et al., 2014b; Shemfe et al., 2016; Wang et al., 2015). Depend on the type of feedstock, several promising technology such as gasification, Fischer-Tropsch synthesis (FTS), hydro-processing technologies, including hydro-treating, deoxygenation, isomerization/hydrocracking and catalytic hydro-thermolysis that convert biomass-based materials into jet fuel substitutes are available at commercial scale or research and development stage (Bezergianni et al., 2009; Mohan et al., 2006; Saidi et al., 2014b). In FTS technology as a developed and commercialized route to transform lignocellulose biomass into jet fuel hydrocarbons range (particularly alkanes), bio-syngas produces via biomass gasification and subsequently cleaning and conditioning of crude syngas will be performed (Liu et al., 2013; Yan et al., 2013). High pressure FT synthesis and upgrading of crude fuels for jet fuel applications is 
the final step. Based on international standards for certifying aviation fuel such as American Society for Testing and Materials (ASTM D1655), the most important specifications required to reach bio-jet-fuels are acceptable viscosity, heating value, electrical conductivity, freeze point temperature, flash point, aromatics content, acidity and mercaptan concentration. Typically the jet fuels are comprised of paraffins, naphthenes and aromatics (Branca et al., 2003; Czernik and Bridgwater, 2004; Oasmaa and Czernik, 1999). Nonetheless, in the well-developed hydrotreating technologies such as FTS, it is hard to attain acceptable compositions of cyclic paraffins and aromatics jet fuels.

Lignin as a main underutilized constituent of lignocellulosic biomass is highly aromatic, with a polymeric structure characterized by ether linkages and hydroxy and methoxy groups and it has been proven to potentially produce biofuels with aromatic structure by various strategies (Saidi et al., 2015a; Saidi et al., 2015b; Zakzeski et al., 2010). Fast pyrolysis of biomass, a process that is relatively well developed, is one of the viable processes to convert lignocellulosic biomass to bio-oils (Akhtar and Amin, 2011; Wang et al., 2012). In fast pyrolysis, lignin is heated in the absence of air to temperatures between about 650 and $800 \mathrm{~K}$ and it will be converted substantially into compounds such as phenol, anisole, guaiacol, cresol, syringol, etc. Products of the conversion of these compounds with $\mathrm{H}_{2}$ include cyclohexanone, and only little research has been done to investigate the catalytic reactions of this compound with $\mathrm{H}_{2}$ (Nimmanwudipong et al., 2011a; Runnebaum et al., 2012). The lignin-derived bio-oils are unable for use directly as a fuel because of detrimental properties compared to petroleum fuels, such as much lower energy density, poor thermal and chemical stabilities, high viscosity and oxygen content. To meet the requirements of the conventional transportation fuels, lignin-derived bio-oils have to be upgraded to eliminate total or partial oxygenates and unsaturated degree prior to its practical 
application as valuable fuel (Alonso et al., 2010; Nimmanwudipong et al., 2011b; Runnebaum et al., 2011). Among the upgrading approaches for jet fuels, hydrodeoxygenation (HDO) is introduced as a promising process to remove the oxygen content under high temperature and pressure of hydrogen in the presence of a catalyst.

Bio-oils derived from fast pyrolysis of lignin are excellent feedstock for production of renewable diesel and jet fuel. Cyclohexanone as an intermediate lignin-derived bio-oil can be directly converted into aromatics in the range of jet fuel hydrocarbons in a catalytic HDO step and consequently these aromatics with low oxygen content can be hydrogenated into cyclic paraffins and olefins.

Numerous researches have presented detailed studies of a wide variety of catalysts and processes for HDO of lignin-derived bio-oils to valuable fuels include metals, metal sulfides, metal phosphides, metal carbides, and metal nitrides on various supports (Badawi et al., 2011; González-Borja and Resasco, 2011; Li et al., 2011; Saidi et al., 2016; Saidi et al., 2015b; Saidi et al., 2014b; Sankaranarayanan et al.; Zhu et al., 2011). Although noble metals such as platinum offer high activities for HDO reactions and hydrogenation of aromatic rings, they are expensive. In a related study, the catalytic transformation of cyclohexanone catalyzed by $\mathrm{Pt} / \mathrm{HZSM}-5$ in the presence of $\mathrm{H}_{2}$ has been investigated by Alvarez et al. (Alvarez et al., 1994) who detected formation of families of products such as cyclic and bicyclic hydrocarbons, tricyclic ketones, cyclohexenylcyclohexanone, cyclohexylcyclohexanone, and phenylcyclohexanone. Also Silva et al. (Silva et al., 2000) reported that cyclohexanone was converted into cyclohexylcyclohexanone via successive steps of Aldol condensation, dehydration, and hydrogenation on a bifunctional Pd/HFAU catalyst. In another work, Nimmanwudipong et al. (Nimmanwudipong et al., 2011a) and Saidi et al. (Saidi et al., 2014a) provided a reaction network for catalytic conversion of 
cyclohexanone by $\mathrm{Pt} / \gamma-\mathrm{Al}_{2} \mathrm{O}_{3}$ in the presence of $\mathrm{H}_{2}$ and observed that the main reaction classes are hydrogenation, dehydrogenation, HDO, dehydration, isomerization, alkylation, and condensation. In the upgrading process of lignin-derived bio-oils, there is a competition between HDO and hydrogenation of aromatic rings. Metals involving iron, cobalt, nickel, platinum, palladium, ruthenium, rhodium and iridium show activity for these reactions. Maier et al. (Maier et al., 1981) and Shin and Keane (Shin and Keane, 2000) investigated the catalytic upgrading of cyclohexanone by supported nickel, finding cyclohexanol, phenol, benzene, cyclohexene, and cyclohexane as the major products. Also Prasomsri et al. (Prasomsri et al., 2014) experiments revealed that over $\mathrm{MoO}_{3}$ catalyst, cyclohexanone conversion proceeds by a deoxygenation pathway leading to the formation of cyclohexene, which is converted to benzene. They concluded that the molybdenum-containing catalyst is selective for $\mathrm{C}-\mathrm{O}$ bond cleavage at low $\mathrm{H}_{2}$ partial pressures (Prasomsri et al., 2014).

Metal sulfide catalysts are another important catalyst type which are widely used in hydroprocessing of lignin-derived bio-oils. These include supported catalysts that incorporate cobalt and molybdenum or nickel and molybdenum. Durand et al. (Durand et al., 1984) used sulfided $\mathrm{NiO}-\mathrm{MoO}_{3} / \gamma-\mathrm{Al}_{2} \mathrm{O}_{3}$ catalyst for the $\mathrm{HDO}$ of a group of alcohols and ketones such as cyclohexanone. They reported that the initial step is hydrogenation of the ketone to the alcohol, which rate is limiting. The second step is transformation of alcohols into olefins by dehydration that is subsequently converted by hydrogenation or hydrogenolysis. Olivas et al. (Olivas et al., 2001) used unsupported Ni-W sulfide catalysts for hydrogenation of cyclohexanone and inferred that these binary sulfides are more active than the single sulfides. In similar research, Lin et al. (Lin et al., 2011) concluded that demethylation, demethoxylation, and deoxygenation reactions 
following saturation of the aromatic ring occurs in guaiacol upgrading with sulfided $\mathrm{CoMo} / \mathrm{Al}_{2} \mathrm{O}_{3}$ and $\mathrm{NiMo} / \mathrm{Al}_{2} \mathrm{O}_{3}$ catalysts.

HDO of phenolic compounds catalyzed by sulfided $\mathrm{CoMo} / \mathrm{Al}_{2} \mathrm{O}_{3}$ was studied by Furimsky et al. (Furimsky et al., 1986). They observed that presulfiding of the catalyst had a significant effect on the conversion of phenols to benzene and cyclohexane. Also in another related work, Vuori et al. (Vuori et al., 1989) reported a benefit of presulfiding of such catalysts in the conversion of guaiacol. Ferrari et al. (Ferrari et al., 2001) considered the effect of $\mathrm{H}_{2} \mathrm{~S}$ partial pressure on HDO of a mixture of phenolic compounds. Their obtained results indicated that increasing the $\mathrm{H}_{2} \mathrm{~S}$ partial pressure led to inhibition of the hydrogenolysis and hydrogenation pathways. Gutierrez et al. (Gutierrez et al., 2009) reported that in HDO process of bio-oils with a conventional sulfided $\mathrm{CoMo} / \mathrm{Al}_{2} \mathrm{O}_{3}$ catalyst, the products were contaminated with sulfur and the catalyst underwent deactivation associated with carbonaceous deposits. Viljava et al. (Viljava et al., 2000) reported that addition of sulfiding agents such as $\mathrm{H}_{2} \mathrm{~S}$ or $\mathrm{CS}_{2}$ to the feed during HDO strongly decreases the initial activity of a sulfided $\mathrm{CoMo} / \mathrm{Al}_{2} \mathrm{O}_{3}$ catalyst. Also Gevert et al. (Gevert et al., 1987) have reported the hydrogenolysis route of $\mathrm{HDO}$ of methylphenols on $\mathrm{CoMo} / \mathrm{Al}_{2} \mathrm{O}_{3}$ catalyst to be more inhibited by $\mathrm{H}_{2} \mathrm{~S}$ than the hydrogenation-hydrogenolysis route.

Since lignin-derived bio-oils such as cyclohexanone are potential feedstocks for production of diesel and jet fuels, it is necessary to study the catalytic upgrading of this type of bio-oil. In the research reported here, we studied the feasibility of catalytic upgrading of cyclohexanone as a good representative of lignin-derived compounds to jet fuel range hydrocarbons. The main focus of this paper is to determine the approximate reaction network of cyclohexanone conversion on conventional sulfided $\mathrm{CoMo} / \mathrm{Al}_{2} \mathrm{O}_{3}$. Sulfided catalyst containing Mo and Co are widely used in petroleum refinery processes such as hydrodesulfurization (HDS) and hydrodenitrogenation 
(HDN) processes. Because of similarities between HDO and these processes, these catalysts have been regarded as good candidates to catalyze bio-oils upgrading. Furthermore to provide a quantitative foundation for cyclohexanone upgrading, the kinetic assessments are done and kinetic parameters are reported at different operating conditions.

\section{Experimental Section}

\subsection{Chemicals}

Cyclohexanone (Merck, 99.8\% GC assay) were used in all experiments. Authentic standards used for identifications of the most abundant products in the catalytic reaction experiments were obtained from Sigma-Aldrich.

\subsection{Commercial Catalyst}

The American Cyanamid HDS $16 \mathrm{~A}$ catalyst $\left(\mathrm{CoMo} / \gamma-\mathrm{Al}_{2} \mathrm{O}_{3}\right)$ is used in this study. The catalyst properties before sulfiding is as follow: surface area, $176 \mathrm{~m}^{2} / \mathrm{g}$; pore volume, $0.50 \mathrm{~cm}^{3} / \mathrm{g}$; Co content, $4.4 \mathrm{wt} \%$; and Mo content, $7.5 \mathrm{wt} \%$. Sulfiding was achieved by passing a flow (20 L/h) of $10 \% \mathrm{H}_{2} \mathrm{~S}$ in $\mathrm{H}_{2}$, while heating at a rate of about $10^{\circ} \mathrm{C} / \mathrm{min}$ to $500^{\circ} \mathrm{C}$. After two hours at $500^{\circ} \mathrm{C}$, the $\mathrm{H}_{2} \mathrm{~S} / \mathrm{H}_{2}$ was replaced by $\mathrm{N}_{2}$ and the reactor cooled to operating temperature. A sample of catalyst powder (less than 100 mesh particle, demonstrated experimentally to be small enough to ensure the lack of interparticle diffusion resistance) was charged to the reactor.

\subsection{Catalytic Reaction and Analysis}

Refinery process of cyclohexanone was carried out at $8( \pm 0.1)$ bar pressure and 573-673 $( \pm 1.5)$ $\mathrm{K}$ in a tubular flow reactor of $14.5 \mathrm{~mm}$ outer diameter, $9 \mathrm{~mm}$ inner diameter and $305 \mathrm{~mm}$ length. 
In a typical experiment, the liquid reactant was injected from an HPLC pump (model Gilson $307)$ in the range of $0.03-0.5( \pm 1 \%) \mathrm{mL} / \mathrm{min}$ to an evaporator at $463 \mathrm{~K}$, and after vaporization, it was mixed with a gas mixture $(40 \mathrm{~L} / \mathrm{h})$ stream of $\mathrm{N}_{2}$ and $\mathrm{H}_{2}(50 \%-50 \%)$ before entering the reactor. In catalyst testing, the particles of the catalysts were placed on the porous plate in the once-through reactor operated in down-flow mode, mixed with about $2 \mathrm{~g}$ of inert, nonporous $\alpha-\mathrm{Al}_{2} \mathrm{O}_{3}$ particles. Fresh catalyst $(0.25-2.00 \mathrm{~g})$ was used for each experiment. Each experiment was typically run for $6 \mathrm{~h}$ of continuous operation.

After upgrading process, liquid products were condensed in an water/ice condenser at 273-277 K. Liquid samples were collected manually and after dilution in acetone, were analyzed using a Bruker 450 gas chromatograph (GC) equipped with an OPTIMA 5 Macherey-Nagel capillary column (30 $\mathrm{m} \times 0.25 \mathrm{~mm}$, with a $0.25 \mu \mathrm{m}$ film thickness) and flame ionization detector (FID). Identification of products in the collected liquid was performed with Shimadzu QP 50/50 gas chromatograph-mass spectrometer (GC-MS) equipped with a SGE BPX5 capillary column $(0.32 \mathrm{~mm} \times 30 \mathrm{~m} \times 0.25 \mu \mathrm{m})$, and helium $(50 \mathrm{~mL} / \mathrm{min})$ used as the carrier gas. The results confirmed by injection of standards on the basis of mass spectra by matching to a Willy library. Also gas samples were analyzed online by GC. A schematic diagram of experimental set up is presented in Figure 1.

\section{Figure 1}

Cyclohexanone conversion was calculated from the flow rate of liquid cyclohexanone to the reactor and the flow rates of the liquid condensate product and gas product streams from the condenser. Conversion $(X)$ and selectivity to various products i $\left(S_{\mathrm{i}}\right)$ are defined as follows:

$$
X=\frac{(\text { moles of cyclohexan one })_{\text {in }}-(\text { moles of cyclohexan one })_{\text {out }}}{(\text { moles of cyclohexan one })_{\text {in }}} * 100 \%
$$


$S_{i}=\frac{\text { molar flow rate of product } i}{\text { molar flow rate of cyclohexan one consumed }}$

\section{Results and Discussion}

The upgrading process of cyclohexanone to jet fuel range hydrocarbons catalyzed by commercial sulfided $\mathrm{CoMo} / \mathrm{Al}_{2} \mathrm{O}_{3}$ was studied under $\mathrm{HDO}$ conditions. As mentioned above, the catalyst was presulfided by $\mathrm{H}_{2} \mathrm{~S}$ stream, but the sulfiding agent was not added to the feed mixture because it was expected that it would have inhibited the reactions. GC analysis of the liquid products samples indicated the formation of complex reaction mixtures in which the main products were benzene, cyclohexene, 2-cyclohexen-1-one, phenol, 2-methylphenol, cyclohexylbenzene, biphenyl, 2-phenylphenol, 2-cyclohexylcyclohexan-1-one, 2-cyclohexylphenol and 2-cyclohexylidenecyclohexane-1-one. Also GC-MS analyses of the product represented that the minor products are methane, methanol, and water. Under the experiment conditions, the conversion data demonstrate a lack of dependence on the mass of catalyst (in the range $0.25-$ $2.00 \mathrm{~g}$ ) at fixed values of the $W H S V$ in the range of 3-120 (g of cyclohexanone)/(g of catalyst $\times$ h), consistent with the inference that extraparticle mass transfer limitations were negligible. Mass transfer analysis demonstrated that the intraparticle mass transfer resistance was negligible. The modified Thiele modulus, $\Phi$, is calculated as follows:

$\Phi=\frac{F_{0 \text { Cyclohexarne }} X_{\text {Cyclohexamne }} V_{p}}{D_{e} C_{\text {Cyclohexarne }} S_{p}{ }^{2} N_{p}}$

where $F_{0 \text {, Cyclohexanone }} X_{\text {Cyclohexanone }}$ is the molar flow rate of cyclohexanone converted inside the catalyst bed $\left(\mathrm{mol} \mathrm{s}^{-1}\right), V_{p}$ is the outer volume of a particle of catalyst, assumed to be spherical 
$\left(\mathrm{m}^{3}\right), C_{\text {Cyclohexanone }}$ is the molar concentration of cyclohexanone $\left(\mathrm{mol} \mathrm{m}^{-3}\right), S_{p}$ is the outer surface area of a particle $\left(\mathrm{m}^{2}\right), N_{p}$ is the number of particles of the bed, and $D_{e}$ is the effective diffusivity $\left(\mathrm{m}^{2} \mathrm{~s}^{-1}\right)$. The effective diffusivity and Knudsen diffusivity, $D_{K}\left(\mathrm{~m}^{2} \mathrm{~s}^{-1}\right)$ are determined by:

$\mathrm{D}_{\mathrm{e}}=\mathrm{D}_{\mathrm{K}} \frac{\varepsilon}{\tau}$

$D_{K}=\frac{d}{3} \sqrt{\frac{8 R T}{\pi M_{\text {Cyclohexarone }}}}$

where $d$ is the average pore diameter $(\mathrm{m})$, and $M_{\text {Cyclohexanone }}$ is the molecular weight of cyclohexanone $\left(\mathrm{kg} \mathrm{mol}^{-1}\right)$, where $\varepsilon$ and $\tau$ are the porosity of the particles and the tortuosity of their pores, respectively. The calculated values of the modified Thiele modulus (Weisz modulus) were less than 0.4 , indicating that the cyclohexanone conversion rate was not limited by internal diffusion and therefore that the catalytic reaction experiments determined intrinsic chemical kinetics. Also the mass balance closures were generally about 100\% (Table 1).

\section{Table 1}

\subsection{Reaction Network for Preparation of Jet Fuel Range Hydrocarbons}

The main purpose of this study is to produce jet fuels range aromatic hydrocarbons using the lignin derived bio-oil. The variety and complexity of the main product distribution of the cyclohexanone conversion makes it challenging to determine the reaction paths. One of our goals was to establish a good approximation of the reaction network based on selectivity-conversion data determining which products are primary and which are non-primary. The evolution of the selectivities of the main products as a function of cyclohexanone conversion in the presence of $\mathrm{H}_{2}$ at 8 bar, $573-673 \mathrm{~K}$, and 3-114 (g of cyclohexanone)/ ( $\mathrm{g}$ of catalyst $\times \mathrm{h}$ ) is presented in Figure 2. Initial selectivities (at zero conversion) are estimated by extrapolation using linear lines 
shown in these figures. The initial selectivities are reported in Table 2. The selectivity-conversion analyses reveals that the main products, benzene, cyclohexene, phenol, and 2-cyclohexen-1-one appeared with positive intercepts on the plots (consistent with the values determined by linear regression), indicating primary products. In contrast, the other main products, 2-methylphenol, cyclohexylbenzene, biphenyl, 2-phenylphenol, 2-cyclohexylcyclohexan-1-one, 2-cyclohexylidenecyclohexane-1-one and 2-cyclohexylphenol appeared with approximately zero intercepts, indicating non-primary products. As indicated in Table 2, the maximum initial selectivity is that for formation of benzene as the main product of HDO.

\section{Figure 2}

\section{Table 2}

The formation of these products in the hydro upgrading of cyclohexanone suggests that HDO (indicated, for example, by the formation of benzene and cyclohexene), dehydrogenation (indicated by formation of 2-cyclohexen-1-one), hydrogenolysis by $\mathrm{O}$-demethylation (indicated, for example, for example, by the formation of phenol and methane) and coupling reactions (indicated, for example, by the formation of biphenyl and ...) are kinetically significant reaction pathways. Thus, an approximate statement of the network for conversion of cyclohexanone by the sulfided $\mathrm{CoMo} / \mathrm{Al}_{2} \mathrm{O}_{3}$ catalyst under our experimental conditions, accounting for just the primary products and the other major products, is that proposed in Figure 3.

\section{Figure 3}

As presented in Figure 3, we suggested a stepwise transformation of bio-oil into the jet fuels range hydrocarbons via different reaction pathways including HDO, hydrogenation, 
dehydrogenation coupling and alkylation. In the primary step, the oxygenated lignin-derived bio-oil (in the present case, cyclohexanone) was converted into low-carbon aromatics such as benzene and cyclohexene through catalytic conversion of bio-oil. Because the liquid hydrocarbons derived from the primary step are essentially composed of low carbon hydrocarbons, the distribution of the carbon numbers in the hydrocarbons should be adjusted to meet the requirements of jet fuels. Thus consequently in the secondary step, bicyclic hydrocarbons were formed by the coupling and alkylation reactions of low-carbon aromatics.

As indicated in Figure 3, we infer that cyclohexene is formed via direct deoxygenation pathway (DDO). Also there are two routes for the conversion of cyclohexanone to benzene: one, dehydrogenation of the cyclohexanone (phenol formation) followed by HDO, and, another, HDO of the cyclohexanone (cyclohexane formation) followed by dehydrogenation pathway. The observation of water as products is consistent with the occurrence of these reactions. The presence of cyclohexene and benzene with high selectivity among the main products shows that the dehydrogenation and HDO reactions that take place on the CoMo catalyst dominate kinetically. We infer that sequential coupling reactions produces hydrocarbons in the range of jet fuel such cyclohexylbenzene, biphenyl, 2-phenylphenol, 2-cyclohexylcyclohexan-1-one, 2-cyclohexylidenecyclohexane-1-one and 2-cyclohexylphenol that are known to take place on acidic surfaces such as that of the alumina support. According to the selectivity-conversion data in Figure 2, the selectivity for one route may decline in favor of another as conversion increases.

\subsection{Kinetic Investigation of Cyclohexanone Conversion}

In kinetic analyses, it is important to determine initial reaction rates, kinetic constants and activation energies as measures of catalytic activity. Due to the complexity and variety of 
products formed in cxclohexanone conversion, we have made the commonly applied simplification that the main reactions occurring in cyclohexanone upgrading are first order. Because catalyst deactivation was observed to be negligible during $6 \mathrm{~h}$ of continuous operation in the experiments, average conversions over the entire $6^{-} \mathrm{h}$ period of time on stream are used to determine the reported rate constants. Conversions of cyclohexanone were determined from changes in the space velocity, and conversions to individual major products were calculated from analyses of those products. Data showing the conversion of cyclohexanone as a function of the inverse $W H S V$ and the conversions to main products at different temperatures in a typical run are presented in Figures 4. As shown in this figure, the conversion data fall near straight lines that pass through the origin, so that the slopes of the lines determine the rates of the reactions. As presented in Figure 4, the conversion of cyclohexanone at a given $W H S V$, and the rate of formation of each of the products, increases with increasing temperature in the observed range, from 573 to $673 \mathrm{~K}$, and at a give temperature, the conversion improves with increasing inverse $W H S V$ at a given temperature. The initial rates of appearance of the various products of cyclohexanone upgrading process (Table 2) show that the primary product formed at the highest initial rate is benzene as the main product of HDO. Eqs. (6) to (10) give more details about how the pseudo-first-order model were developed from the data. To estimate rate constants for the reactions, plots of $\left(1-X_{i}\right)$ (where $X_{i}$ is the conversion of cyclohexanone to species $\mathrm{i}$ ) on logarithmic scales vs. inverse space velocity is applied (Figure 5). As indicated in this figure, the slopes of the linear plots represent pseudo first-order reactions. As reported in Table 2, the maximum rate constants among those determined in this work at each temperature are those for the formation of benzene. The pseudo first-order rate constants for benzene formation were 
determined to be $0.95,2.11$, and $2.85 \mathrm{~L} /(\mathrm{g}$ of catalyst $\times \mathrm{h})$, respectively, at 573,623 , and $673 \mathrm{~K}$ and a pressure of 8 bar.

$$
\begin{aligned}
& r_{i}=\frac{d c_{i}}{d\left(c_{\text {Cyclohexamne }, 0} / W H S V\right)}=k_{i} c_{\text {Cyclohexamne }} \\
& c_{i}=c_{\text {Cyclohexamne }, 0} X_{i} \\
& c_{\text {Cyclohexarne }}=c_{\text {Cyclohexarone }, 0}\left(1-X_{i}\right) \\
& r_{i}=\frac{d X_{i}}{d\left(c_{\text {Cyclohexamne }, 0} / W H S V\right)}=k_{i}\left(1-X_{i}\right) \\
& \ln \left(1-X_{i}\right)=-k_{i}\left(c_{\text {Cyclohexanne }, 0} / W H S V\right)
\end{aligned}
$$

\section{Figure 4}

\section{Figure 5}

These values of the apparent rate constants were applied to calculate values of the apparent activation energies on the basis of the Arrhenius equation. The corresponding plots are presented in Figure 6 and the estimated values of apparent activation energies are reported in Table 2. The values of these apparent activation energies for the formation of 2-cyclohexen-1-one, cyclohexene and benzene are approximately $42.4 \mathrm{~kJ} / \mathrm{mol}, 35.6 \mathrm{~kJ} / \mathrm{mol}$ and $26.2 \mathrm{~kJ} / \mathrm{mol}$, respectively.

\section{Figure 6}

\subsection{Sensitivity Analysis of Operating Condition}

The effects of operating conditions including temperature, pressure and space velocity on the cyclohexanone conversion to jet fuel range hydrocarbons was investigated in Figures 7 and 8 . 
Reaction temperature has an important impact on the conversion of cyclohexanone. As can be seen from Figure 7, the conversion of cyclohexanone at 8 bar and different space velocities gradually increased with increasing temperatures. For example at 0.3 (g of catalyst $\times \mathrm{h}) /(\mathrm{g}$ of cyclohexanone), the overall conversion improved from 7 to $18 \%$ as the temperature increased from 573 to $673 \mathrm{~K}$. As shown in Figure 8, at $623 \mathrm{~K}$ and different space velocities, increasing the operating pressure improves the overall conversion. The effect of pressure on selectivity for the formation of the major products is shown in Figure 9. Under our conditions, higher pressures not only enhance the overall conversion of bio-oil into hydrocarbons, but also increase the selctivities to deoxygenated products like benzene and cyclohexene. From the point of view of chemical equilibrium, increasing pressure will result in the decrease of equilibrium constants and therefore is not beneficial to the aromatic coupling. As a result, the selectivity for formation of bicyclic hydrocarbons products decreased with increasing pressure. We infer that if oxygen removal is the principal processing goal, higher temperatures and pressures are more favorable, within the range of our operating conditions.

Figure 7

Figure 8

Figure 9

\section{Discussion}

The results presented here are broadly consistent and more complete than reported data for cyclohexanone upgrading catalyzed by sulfided $\mathrm{CoMo} / \mathrm{Al}_{2} \mathrm{O}_{3}$ under $\mathrm{HDO}$ conditions (Gutierrez et al., 2009; Jongerius et al., 2013; Jongerius et al., 2012; Nimmanwudipong et al., 2011a; Runnebaum et al., 2012; Viljava et al., 2000). It is necessary to mention that because of 
differences in the catalysts and operating conditions, there are some differences in the main products. The reported kinetics data in the present work provides a preliminary quantitative basis for identifying the reaction pathways and determining the initial product distributions at several operating conditions. The selectivity-conversion data presented in Figure 2 is used for identifying primary and non-primary products as these are defined empirically, with benzene, cyclohexene, phenol, and 2-cyclohexen-1-one being primary products and other bicyclic derivatives being non-primary products. If a non-primary product is formed faster than primary product, it may detect with a positive intercept on a selectivity-conversion plot indicating a primary product.

For example, the selectivity-conversion data (Figure 2) clearly point to benzene as a primary product, but as suggested in reaction network presented in Figure 3, we regard it as a non-primary product and suggest that it forms rapidly from one or more intermediates (ring dehydrogenation and breaking of a carbon-oxygen bond). Extensive formation of 12-carbon bicyclic compounds in the range of jet fuels as major products confirms the occurrence of coupling reactions. Based on suggested network, cyclohexene and 2-cyclohexen-1-one as the intermediates products might participate in a coupling reaction with cyclohexanone to form 2-cyclohexylcyclohexan-1-one and cyclohexylidenecyclohexan-1-one, respectively and consequently cyclohexylidenecyclohexan-1-one could be converted into 2-phenylphenol by dehydrogenation. Also as presented in Figure 3, cyclohexylbenzene as another bicyclic deoxygenated product could be produced by coupling of benzene with cyclohexene and it could be subsequently converted into biphenyl by dehydrogenation reaction. Biphenyl could also be formed by HDO of 2-phenylphenol, and 2-cyclohexylphenol could be formed by coupling of phenol with cyclohexene. 
The oxygen removal was largely attributed to the role of CoMo in activating $\mathrm{H}_{2}$ for HDO reactions. CoMo sites catalyze hydrogenation of cyclohexanone to $\mathrm{C}_{6}$ cyclic hydrocarbons, dehydrogenation to form phenol, and HDO to form benzene and cyclohexene, which are kinetically significant reactions under our experimental conditions. Also alkylation and coupling reactions are expected to occur in the presence of acidic sites on the catalyst support $\left(\gamma-\mathrm{Al}_{2} \mathrm{O}_{3}\right)$. The data reported in Table 2 indicates that among the various reactions on sulfided $\mathrm{CoMo} / \mathrm{Al}_{2} \mathrm{O}_{3}$, HDO is characterized by the highest rate and that selectivities for oxygen removal are favored by operation at higher temperatures and pressures. Increasing the temperature enhances the selectivity for HDO. The results presented here may be of value for preliminary design predictions for the conversion of lignin-derived bio-oils to valuable fuels such as jet fuel range hydrocarbons, but it is evident from the complexity of the feedstocks and of the reaction networks of the individual compounds that much work remains to be done to provide a firm foundation for even rough design predictions.

\section{Conclusions}

Production of jet fuel range hydrocarbons was conducted by the catalytic upgrading of the cyclohexanone as an intermediate lignin derived bio-oil catalyzed by sulfided $\mathrm{CoMo} / \mathrm{Al}_{2} \mathrm{O}_{3}$ in the temperature range of 573 to $673 \mathrm{~K}$ and the pressure range of 8 to 20 bar. An approximate reaction network accounts for HDO of cyclohexanone to form benzene and cyclohexene and dehydrogenation to form 2-cyclohexen-1-one that take place on the CoMo catalyst, followed by coupling and alkylation reactions to give bicyclic hydrocarbons such as cyclohexylbenzene, biphenyl, 2-phenylphenol, 2-cyclohexylphenol, 2-cyclohexylcyclohexan-1-one, and 2-cyclohexylidenecyclohexane-1-one that take place on acidic surfaces such as that of the 
alumina support. Sensitivity analysis of operating conditions reveals that oxygen removal of cyclohexanone is favored by operation at higher temperatures and pressures. The selectivity-conversion data revealed that cyclohexanone transformation can be appropriately represented by the pseudo-first-order kinetics. To provide a quantitative framework for considering reaction mechanisms and interpreting data, the kinetic parameters for each reaction in the presented network are estimated. The experimental research here may provide a starting point for upgrading bio-oils to bendable hydrocarbons in the range of jet fuels or other valuable chemicals. 


\section{Acknowledgements}

The authors gratefully acknowledge the support (Grant No. 95821383) from Iran National Science Foundation (INSF).

This work has been financially supported by the research deputy of Shahrekord University. The grant number was 94PRM2M35963. 


\section{References}

Akhtar, J., Amin, N.A.S., 2011. A review on process conditions for optimum bio-oil yield in hydrothermal liquefaction of biomass. Renewable and Sustainable Energy Reviews 15, 16151624.

Alonso, D.M., Bond, J.Q., Dumesic, J.A., 2010. Catalytic conversion of biomass to biofuels. Green Chemistry 12, 1493-1513.

Alvarez, F., Ribeiro, F.R., Guisnet, M., 1994. Transformation of cyclohexanone on PtHZSM5 catalysts—reaction scheme. Journal of molecular catalysis 92, 67-79.

Badawi, M., Paul, J.-F., Cristol, S., Payen, E., 2011. Guaiacol derivatives and inhibiting species adsorption over MoS2 and CoMoS catalysts under HDO conditions: A DFT study. Catalysis Communications 12, 901-905.

Bezergianni, S., Kalogianni, A., Vasalos, I.A., 2009. Hydrocracking of vacuum gas oil-vegetable oil mixtures for biofuels production. Bioresource Technology 100, 3036-3042.

Branca, C., Giudicianni, P., Di Blasi, C., 2003. GC/MS Characterization of Liquids Generated from Low-Temperature Pyrolysis of Wood. Industrial \& Engineering Chemistry Research 42, 3190-3202.

Czernik, S., Bridgwater, A.V., 2004. Overview of Applications of Biomass Fast Pyrolysis Oil. Energy \& Fuels 18, 590-598.

Durand, R., Geneste, P., Moreau, C., Pirat, J., 1984. Heterogeneous hydrodeoxygenation of ketones and alcohols on sulfided $\mathrm{NiO} \square \mathrm{MoO} 3 \gamma-\mathrm{Al} 2 \mathrm{O} 3$ catalyst. Journal of Catalysis 90, 147149. 
Ferrari, M., Maggi, R., Delmon, B., Grange, P., 2001. Influences of the Hydrogen Sulfide Partial Pressure and of a Nitrogen Compound on the Hydrodeoxygenation Activity of a CoMo/Carbon Catalyst. Journal of Catalysis 198, 47-55.

Furimsky, E., Mikhlin, J.A., Jones, D.Q., Adley, T., Baikowitz, H., 1986. On the mechanism of hydrodeoxygenation of ortho substituted phenols. The Canadian Journal of Chemical Engineering 64, 982-985.

Gevert, B.S., Otterstedt, J.E., Massoth, F.E., 1987. Kinetics of the HDO of methyl-substituted phenols. Applied Catalysis 31, 119-131.

González-Borja, M.Á., Resasco, D.E., 2011. Anisole and Guaiacol Hydrodeoxygenation over Monolithic Pt-Sn Catalysts. Energy \& Fuels 25, 4155-4162.

Gutierrez, A., Kaila, R.K., Honkela, M.L., Slioor, R., Krause, A.O.I., 2009. Hydrodeoxygenation of guaiacol on noble metal catalysts. Catalysis Today 147, 239-246.

Hosseinzadeh, M.B., Rezazadeh, S., Rahimpour, H.R., Taghvaei, H., Rahimpour, M.R., 2015. Upgrading of lignin-derived bio-oil in non-catalytic plasma reactor: Effects of operating parameters on 4-methylanisole conversion. Chemical Engineering Research and Design 104, 296-305.

Jongerius, A.L., Bruijnincx, P.C.A., Weckhuysen, B.M., 2013. Liquid-phase reforming and hydrodeoxygenation as a two-step route to aromatics from lignin. Green Chemistry 15, 30493056.

Jongerius, A.L., Jastrzebski, R., Bruijnincx, P.C.A., Weckhuysen, B.M., 2012. CoMo sulfidecatalyzed hydrodeoxygenation of lignin model compounds: An extended reaction network for the conversion of monomeric and dimeric substrates. Journal of Catalysis 285, 315-323. 
Li, K., Wang, R., Chen, J., 2011. Hydrodeoxygenation of Anisole over Silica-Supported Ni2P, MoP, and NiMoP Catalysts. Energy \& Fuels 25, 854-863.

Lin, Y.-C., Li, C.-L., Wan, H.-P., Lee, H.-T., Liu, C.-F., 2011. Catalytic Hydrodeoxygenation of Guaiacol on Rh-Based and Sulfided CoMo and NiMo Catalysts. Energy \& Fuels 25, 890-896.

Liu, G., Yan, B., Chen, G., 2013. Technical review on jet fuel production. Renewable and Sustainable Energy Reviews 25, 59-70.

Maier, W., Bergmann, K., Bleicher, W., Schleyer, P., 1981. Heterogeneous deoxygenation of ketones. Tetrahedron Letters 22, 4227-4230.

Mohan, D., Pittman, C.U., Steele, P.H., 2006. Pyrolysis of Wood/Biomass for Bio-oil: A Critical Review. Energy \& Fuels 20, 848-889.

Naik, D.V., Kumar, V., Prasad, B., Behera, B., Atheya, N., Singh, K.K., Adhikari, D.K., Garg, M.O., 2014. Catalytic cracking of pyrolysis oil oxygenates (aliphatic and aromatic) with vacuum gas oil and their characterization. Chemical Engineering Research and Design 92, 1579-1590.

Nimmanwudipong, T., Runnebaum, R., Tay, K., Block, D., Gates, B., 2011a. Cyclohexanone Conversion Catalyzed by Pt/ $\gamma$-Al2O3: Evidence of Oxygen Removal and Coupling Reactions. Catalysis Letters 141, 1072-1078.

Nimmanwudipong, T., Runnebaum, R.C., Block, D.E., Gates, B.C., 2011b. Catalytic Conversion of Guaiacol Catalyzed by Platinum Supported on Alumina: Reaction Network Including Hydrodeoxygenation Reactions. Energy \& Fuels 25, 3417-3427.

Oasmaa, A., Czernik, S., 1999. Fuel Oil Quality of Biomass Pyrolysis OilsState of the Art for the End Users. Energy \& Fuels 13, 914-921.

Olivas, A., Samano, E., Fuentes, S., 2001. Hydrogenation of cyclohexanone on nickel-tungsten sulfide catalysts. Applied Catalysis A: General 220, 279-285. 
Prasomsri, T., Shetty, M., Murugappan, K., Roman-Leshkov, Y., 2014. Insights into the catalytic activity and surface modification of $\mathrm{MoO} 3$ during the hydrodeoxygenation of lignin-derived model compounds into aromatic hydrocarbons under low hydrogen pressures. Energy \& Environmental Science 7, 2660-2669.

Rahimpour, H.R., Saidi, M., Rostami, P., Gates, B.C., Rahimpour, M.R., 2016. Experimental Investigation on Upgrading of Lignin-Derived Bio-Oils: Kinetic Analysis of Anisole Conversion on Sulfided CoMo/A12O3 Catalyst. International Journal of Chemical Kinetics 48, 702-713.

Runnebaum, R.C., Lobo-Lapidus, R.J., Nimmanwudipong, T., Block, D.E., Gates, B.C., 2011. Conversion of Anisole Catalyzed by Platinum Supported on Alumina: The Reaction Network. Energy \& Fuels 25, 4776-4785.

Runnebaum, R.C., Nimmanwudipong, T., Block, D.E., Gates, B.C., 2012. Catalytic conversion of compounds representative of lignin-derived bio-oils: a reaction network for guaiacol, anisole, 4-methylanisole, and cyclohexanone conversion catalysed by Pt/[gamma]-Al2O3. Catalysis Science \& Technology 2, 113-118.

Saidi, M., Rahimpour, H.R., Rahzani, B., Rostami, P., Gates, B.C., Rahimpour, M.R., 2016. Hydroprocessing of 4-Methylanisole as a Representative of Lignin-derived Bio-oils Catalyzed by Sulfided CoMo/ $\gamma$-Al2O3: A Semiquantitative Reaction Network. Canadian Journal of Chemical Engineering.

Saidi, M., Rahimpour, M.R., Raeissi, S., 2015a. Upgrading Process of 4-Methylanisole as a Lignin-Derived Bio-Oil Catalyzed by Pt/ $\gamma$-Al2O3: Kinetic Investigation and Reaction Network Development. Energy \& Fuels. 
Saidi, M., Rostami, P., Rahimpour, H.R., Roshanfekr Fallah, M.A., Rahimpour, M.R., Gates, B.C., Raeissi, S., 2015b. Kinetics of Upgrading of Anisole with Hydrogen Catalyzed by Platinum Supported on Alumina. Energy \& Fuels 29, 4990-4997.

Saidi, M., Rostami, P., Rahimpour, M.R., Gates, B.C., Raeissi, S., 2014a. Upgrading of LigninDerived Bio-oil Components Catalyzed by Pt/ $\gamma$-Al2O3: Kinetics and Reaction Pathways Characterizing Conversion of Cyclohexanone with H2. Energy \& Fuels 29, 191-199.

Saidi, M., Samimi, F., Karimipourfard, D., Nimmanwudipong, T., Gates, B.C., Rahimpour, M.R., 2014b. Upgrading of lignin-derived bio-oils by catalytic hydrodeoxygenation. Energy \& Environmental Science 7, 103-129.

Sankaranarayanan, T.M., Berenguer, A., Ochoa-Hernández, C., Moreno, I., Jana, P., Coronado, J.M., Serrano, D.P., Pizarro, P., Hydrodeoxygenation of anisole as bio-oil model compound over supported Ni and Co catalysts: Effect of metal and support properties. Catalysis Today.

Shemfe, M.B., Fidalgo, B., Gu, S., 2016. Heat integration for bio-oil hydroprocessing coupled with aqueous phase steam reforming. Chemical Engineering Research and Design 107, 73-80.

Shin, E.-J., Keane, M.A., 2000. Gas-phase hydrogenation/hydrogenolysis of phenol over supported nickel catalysts. Industrial \& Engineering Chemistry Research 39, 883-892.

Silva, A., Alvarez, F., Ribeiro, F.R., Guisnet, M., 2000. Synthesis of cyclohexylcyclohexanone on bifunctional Pd faujasites: Influence of the balance between the acidity and the metallic function. Catalysis today 60, 311-317.

Viljava, T.R., Komulainen, R.S., Krause, A.O.I., 2000. Effect of H2S on the stability of $\mathrm{CoMo} / \mathrm{Al} 2 \mathrm{O} 3$ catalysts during hydrodeoxygenation. Catalysis Today 60, 83-92.

Vuori, A., Helenius, A., Bredenberg, J.B.S., 1989. Influence of sulphur level on hydrodeoxygenation. Applied Catalysis 52, 41-56. 
Wang, J., Bi, P., Zhang, Y., Xue, H., Jiang, P., Wu, X., Liu, J., Wang, T., Li, Q., 2015. Preparation of jet fuel range hydrocarbons by catalytic transformation of bio-oil derived from fast pyrolysis of straw stalk. Energy 86, 488-499.

Wang, Y., He, T., Liu, K., Wu, J., Fang, Y., 2012. From biomass to advanced bio-fuel by catalytic pyrolysis/hydro-processing: Hydrodeoxygenation of bio-oil derived from biomass catalytic pyrolysis. Bioresource Technology 108, 280-284.

Yan, Q., Yu, F., Liu, J., Street, J., Gao, J., Cai, Z., Zhang, J., 2013. Catalytic conversion wood syngas to synthetic aviation turbine fuels over a multifunctional catalyst. Bioresource Technology 127, 281-290.

Zakzeski, J., Bruijnincx, P.C.A., Jongerius, A.L., Weckhuysen, B.M., 2010. The Catalytic Valorization of Lignin for the Production of Renewable Chemicals. Chemical Reviews 110, $3552-3599$.

Zhu, X., Lobban, L.L., Mallinson, R.G., Resasco, D.E., 2011. Bifunctional transalkylation and hydrodeoxygenation of anisole over a Pt/HBeta catalyst. Journal of Catalysis 281, 21-29. 
List of Tables

Table 1. Mass balance closures for transformation of cyclohexanone at different operating conditions.

Table 2. Kinetic parameters for conversion of cyclohexanone into jet fuel hydrocarbons range catalyzed by sulfided $\mathrm{CoMo} / \mathrm{Al}_{2} \mathrm{O}_{3}$ in the temperature range of 573 to $673 \mathrm{~K}$ and the pressure range of 8 to 20 bar. 
Table 1

\begin{tabular}{|c|c|c|c|c|c|c|c|}
\hline $\begin{array}{l}\text { Experiment } \\
\text { number }\end{array}$ & $\begin{array}{l}\text { Mass balance } \\
\text { closure }(\%)\end{array}$ & $\begin{array}{l}\text { Time on stream } \\
(\mathrm{min})\end{array}$ & $\begin{array}{l}\text { Liquid flow rate } \\
(\mathrm{mL} / \mathrm{min})\end{array}$ & $\begin{array}{l}\text { Mass of liquid } \\
\text { fed }(\mathrm{g})\end{array}$ & $\begin{array}{l}\text { Mass of liquid collected } \\
\text { from condenser }(\mathrm{g})\end{array}$ & $\begin{array}{l}\text { Mass of reactant leaving } \\
\text { condenser as vapor }(\mathrm{g})\end{array}$ & $\begin{array}{l}\text { Approximate mass of } \\
\text { liquid remaining in } \\
\text { condenser }(\mathrm{g})\end{array}$ \\
\hline 1 & 99.14 & 360 & 0.03 & 10.24 & 9.03 & 0.12 & 1 \\
\hline 2 & 101.68 & 360 & 0.03 & 10.24 & 9.28 & 0.13 & 1 \\
\hline 3 & 100.97 & 360 & 0.05 & 17.06 & 16.03 & 0.2 & 1 \\
\hline 4 & 100.44 & 360 & 0.05 & 17.06 & 15.98 & 0.16 & 1 \\
\hline 5 & 99.04 & 360 & 0.1 & 34.13 & 32.25 & 0.55 & 1 \\
\hline 6 & 98.07 & 360 & 0.1 & 34.13 & 31.98 & 0.49 & 1 \\
\hline 7 & 97.27 & 360 & 0.5 & 170.64 & 163.21 & 1.78 & 1 \\
\hline 8 & 104.90 & 180 & 0.03 & 5.12 & 4.25 & 0.12 & 1 \\
\hline 9 & 96.30 & 180 & 0.03 & 5.12 & 3.79 & 0.14 & 1 \\
\hline 10 & 102.09 & 180 & 0.05 & 8.53 & 7.50 & 0.21 & 1 \\
\hline 11 & 99.62 & 180 & 0.05 & 8.53 & 7.35 & 0.15 & 1 \\
\hline 12 & 100.27 & 180 & 0.1 & 17.06 & 15.57 & 0.54 & 1 \\
\hline 13 & 98.92 & 180 & 0.1 & 17.06 & 15.39 & 0.49 & 1 \\
\hline 14 & 100.57 & 180 & 0.5 & 85.32 & 83.24 & 1.57 & 1 \\
\hline 15 & 102.20 & 150 & 0.03 & 4.27 & 3.25 & 0.11 & 1 \\
\hline 16 & 99.86 & 150 & 0.03 & 4.27 & 3.13 & 0.13 & 1 \\
\hline 17 & 101.27 & 150 & 0.05 & 7.11 & 6.03 & 0.17 & 1 \\
\hline 18 & 99.16 & 150 & 0.05 & 7.11 & 5.89 & 0.16 & 1 \\
\hline 19 & 96.41 & 150 & 0.1 & 14.22 & 12.04 & 0.67 & 1 \\
\hline 20 & 95.01 & 150 & 0.1 & 14.22 & 11.98 & 0.53 & 1 \\
\hline 21 & 100.38 & 150 & 0.5 & 71.1 & 68.76 & 1.61 & 1 \\
\hline 22 & 98.16 & 120 & 0.03 & 3.41 & 2.21 & 0.14 & 1 \\
\hline 23 & 102.18 & 120 & 0.05 & 5.69 & 4.592 & 0.22 & 1 \\
\hline 24 & 99.89 & 120 & 0.1 & 11.38 & 9.82 & 0.54 & 1 \\
\hline 25 & 99.57 & 120 & 0.5 & 56.88 & 54.06 & 1.58 & 1 \\
\hline
\end{tabular}


Table 2

\begin{tabular}{|c|c|c|c|c|c|}
\hline Component & $T, \mathrm{~K}$ & $\begin{array}{c}\text { Initial } \\
\text { Selectivity }\end{array}$ & $\begin{array}{l}\text { Rate, } \mathrm{mol} / \mathrm{g} \text { of } \\
\text { catalyst } \times \mathrm{h}\end{array}$ & $\begin{array}{l}k_{\mathrm{i}}, \mathrm{L} /(\mathrm{g} \text { of } \\
\text { catalyst } \times \mathrm{h}\end{array}$ & $E, \mathrm{kJmol}^{-1}$ \\
\hline \multirow{3}{*}{ Benzene } & 573 & 0.416 & $5.16 \times 10^{-4}$ & 0.95 & \multirow{3}{*}{35.6} \\
\hline & 623 & 0.459 & $6.84 \times 10^{-4}$ & 2.11 & \\
\hline & 673 & 0.440 & $1.25 \times 10^{-3}$ & 2.85 & \\
\hline \multirow{3}{*}{ Cyclohexene } & 573 & 0.362 & $4.14 \times 10^{-4}$ & 0.77 & \multirow{3}{*}{26.2} \\
\hline & 623 & 0.333 & $4.71 \times 10^{-4}$ & 1.41 & \\
\hline & 673 & 0.285 & $7.76 \times 10^{-4}$ & 1.73 & \\
\hline \multirow{3}{*}{ 2-Cyclohexen-1-one } & 573 & 0.082 & $3.57 \times 10^{-4}$ & 0.62 & \multirow{3}{*}{42.4} \\
\hline & 623 & 0.125 & $7.51 \times 10^{-4}$ & 1.96 & \\
\hline & 673 & 0.175 & $1.02 \times 10^{-3}$ & 2.27 & \\
\hline \multirow{3}{*}{ Phenol } & 573 & 0.108 & $2.80 \times 10^{-4}$ & 0.50 & \multirow{3}{*}{43.3} \\
\hline & 623 & 0.102 & $5.27 \times 10^{-4}$ & 1.42 & \\
\hline & 673 & 0.121 & $9.00 \times 10^{-4}$ & 1.90 & \\
\hline \multirow{3}{*}{ 2-Methylphenol } & 573 & 0.002 & $1.53 \times 10^{-5}$ & 0.03 & \multirow{3}{*}{91.3} \\
\hline & 623 & 0.002 & $5.20 \times 10^{-5}$ & 0.13 & \\
\hline & 673 & 0.009 & $2.55 \times 10^{-4}$ & 0.52 & \\
\hline \multirow{3}{*}{ Cyclohexylbenzene } & 573 & 0.009 & $1.28 \times 10^{-4}$ & 0.10 & \multirow{3}{*}{105.4} \\
\hline & 623 & 0.007 & $8.22 \times 10^{-4}$ & 2.33 & \\
\hline & 673 & 0.008 & $1.22 \times 10^{-3}$ & 2.48 & \\
\hline \multirow{3}{*}{ Biphenyl } & 573 & 0.008 & $3.97 \times 10^{-5}$ & 0.07 & \multirow{3}{*}{54.5} \\
\hline & 623 & 0.009 & $4.89 \times 10^{-5}$ & 0.13 & \\
\hline & 673 & 0.007 & $1.98 \times 10^{-4}$ & 0.39 & \\
\hline \multirow{3}{*}{ 2-Phenylphenol } & 573 & 0.007 & $6.22 \times 10^{-5}$ & 0.10 & \multirow{3}{*}{97.8} \\
\hline & 623 & 0.007 & $1.58 \times 10^{-4}$ & 0.40 & \\
\hline & 673 & 0.006 & $9.81 \times 10^{-4}$ & 2.14 & \\
\hline \multirow{3}{*}{ 2-Cyclohexylcyclohexan-1-one } & 573 & 0.005 & $1.28 \times 10^{-4}$ & 0.23 & \multirow{3}{*}{25.9} \\
\hline & 623 & 0.006 & $1.66 \times 10^{-4}$ & 0.43 & \\
\hline & 673 & 0.007 & $2.58 \times 10^{-4}$ & 0.51 & \\
\hline \multirow{3}{*}{$\begin{array}{l}\text { 2-Cyclohexylidenecyclohexane }-1-0 \\
\text { ne }\end{array}$} & 573 & 0.037 & $5.16 \times 10^{-4}$ & 0.74 & \multirow{3}{*}{39.5} \\
\hline & 623 & 0.036 & $7.13 \times 10^{-4}$ & 2.07 & \\
\hline & 673 & 0.022 & $1.03 \times 10^{-3}$ & 2.49 & \\
\hline \multirow{3}{*}{ 2-Cyclohexylphenol } & 573 & 0.007 & $5.20 \times 10^{-5}$ & 0.09 & \multirow{3}{*}{76.6} \\
\hline & 623 & 0.006 & $1.57 \times 10^{-4}$ & 0.48 & \\
\hline & 673 & 0.006 & $4.46 \times 10^{-4}$ & 0.96 & \\
\hline
\end{tabular}




\section{List of Figures}

Figure 1. Experimental setup, fixed-bed tubular micro-flow reactor.

Figure 2. Selectivity for the formation of the main products in the conversion of cyclohexanone catalyzed by $\mathrm{CoMo} / \mathrm{Al}_{2} \mathrm{O}_{3}$ in the presence of $\mathrm{H}_{2}$ at $\mathrm{P}=8$ bar and (a) $\mathrm{T}=573 \mathrm{~K}$, (b) $\mathrm{T}=623 \mathrm{~K}$ and $(\mathrm{c}) \mathrm{T}=673 \mathrm{~K}$.

Figure 3. Approximate reaction network for the conversion of cyclohexanone into jet fuel hydrocarbons range catalyzed by sulfided $\mathrm{CoMo} / \mathrm{Al}_{2} \mathrm{O}_{3}$ in the temperature range of 573 to $673 \mathrm{~K}$ and the pressure range of 8 to 20 bar. The related kinetic parameters of proposed network are summarized in Table 2.

Figure 4. A Plot of conversion to main product as a function of inverse space velocity to determine reactions rate at 8 bar and (a) $\mathrm{T}=573 \mathrm{~K}$, (b) $\mathrm{T}=623 \mathrm{~K}$ and (c) $\mathrm{T}=673 \mathrm{~K}$; the term $X_{\mathrm{i}}$ represents the conversion to product $\mathrm{i}$.

Figure 5. Conversion of cyclohexanone in the presence of $\mathrm{H}_{2}$ to determine rate constants at $\mathrm{P}=8$ bar and (a) $\mathrm{T}=573 \mathrm{~K}$, (b) $\mathrm{T}=623 \mathrm{~K}$ and (c) $\mathrm{T}=673 \mathrm{~K}$; where $X_{i}$ is conversion of cyclohexanone on a logarithmic scale.

Figure 6. Apparent activation energies for formation of main products in upgrading process catalyzed by $\mathrm{CoMo} / \gamma \mathrm{Al}_{2} \mathrm{O}_{3}$, where $\mathrm{k}$ is rate constant on a logarithmic scale.

Figure 7. Conversion of cyclohexanone at $\mathrm{P}=8$ bar, different operating temperature and WHSV.

Figure 8. Conversion of cyclohexanone at $\mathrm{T}=623 \mathrm{~K}$, different operating pressure and $W H S V$.

Figure 9. Pressure dependence of selectivity for the formation of the main products of the reaction of cyclohexanone with $\mathrm{H}_{2}$ at $623 \mathrm{~K}$ and $W H S V=3.5$ (g cyclohexanone)/(g catalyst $\times$ h) 


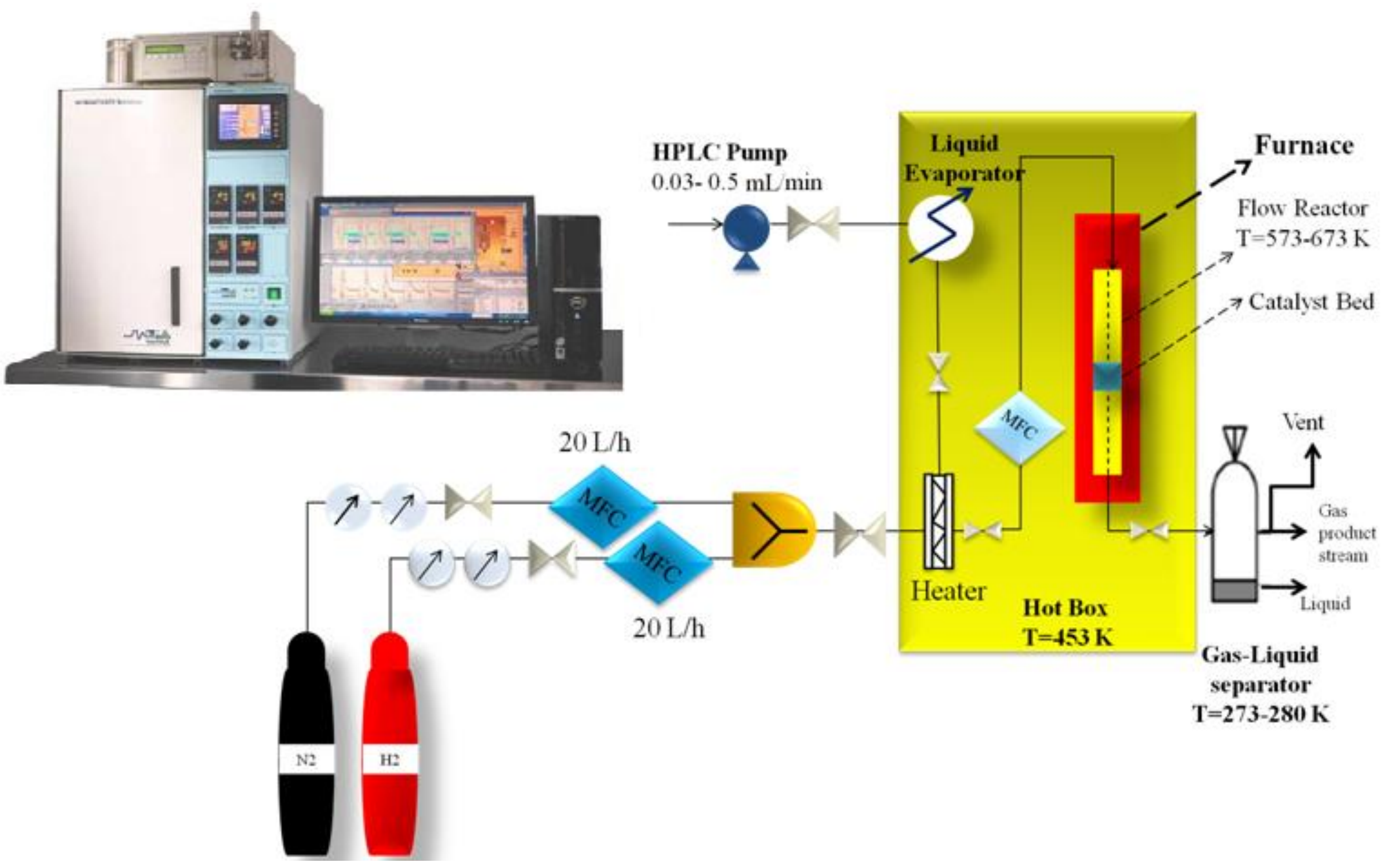

Figure 1 

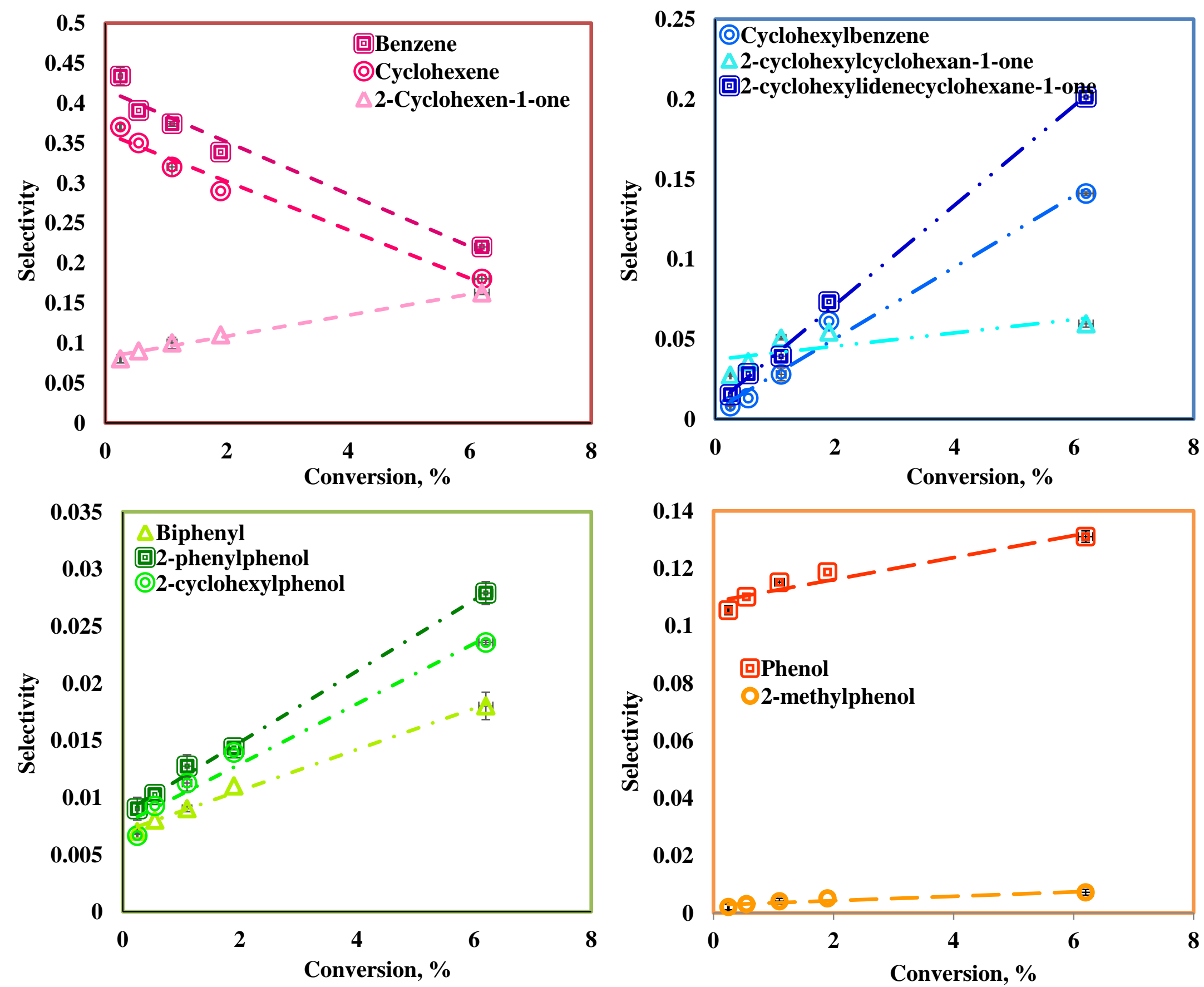

Figure 2-a 

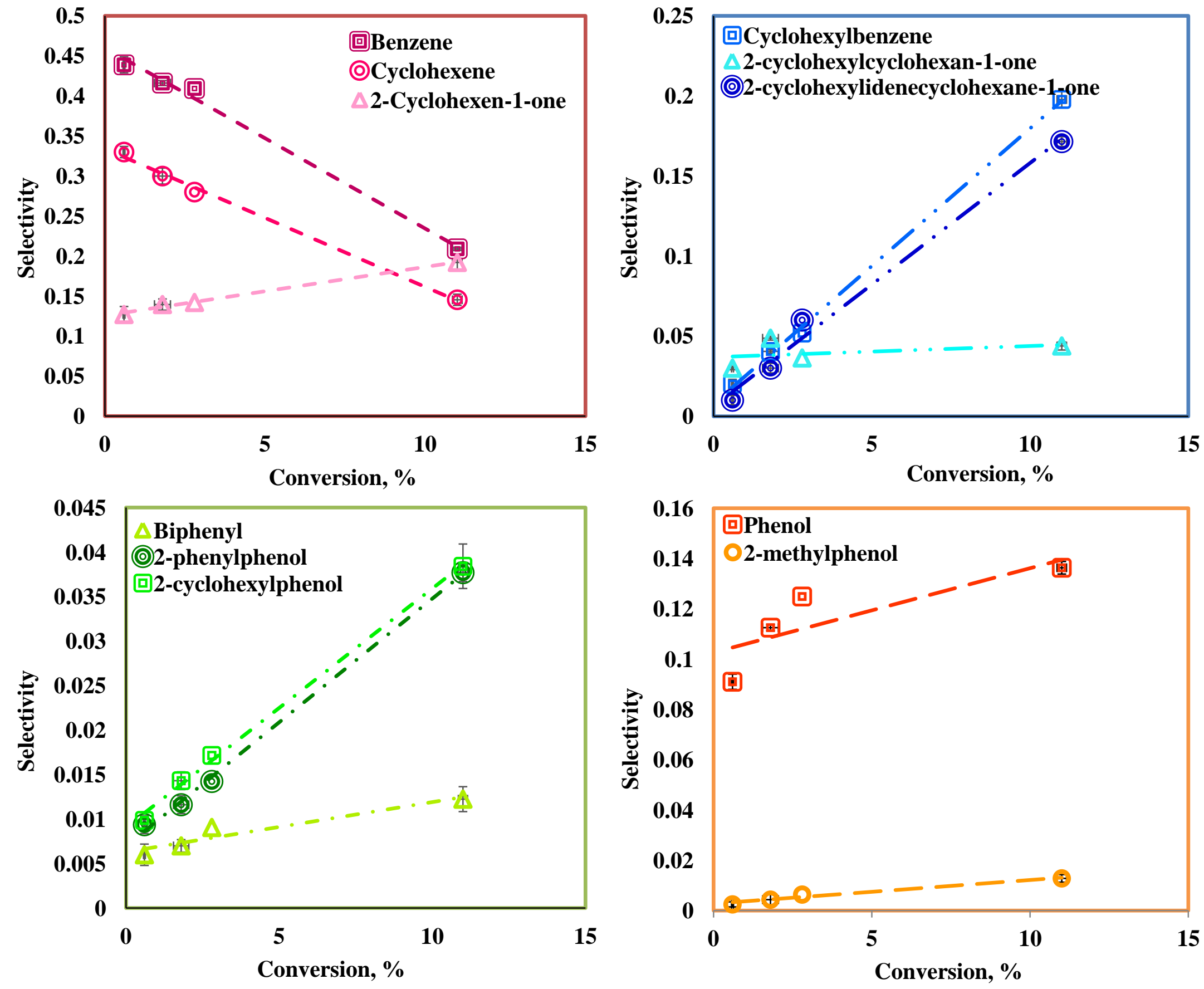

Figure 2-b 

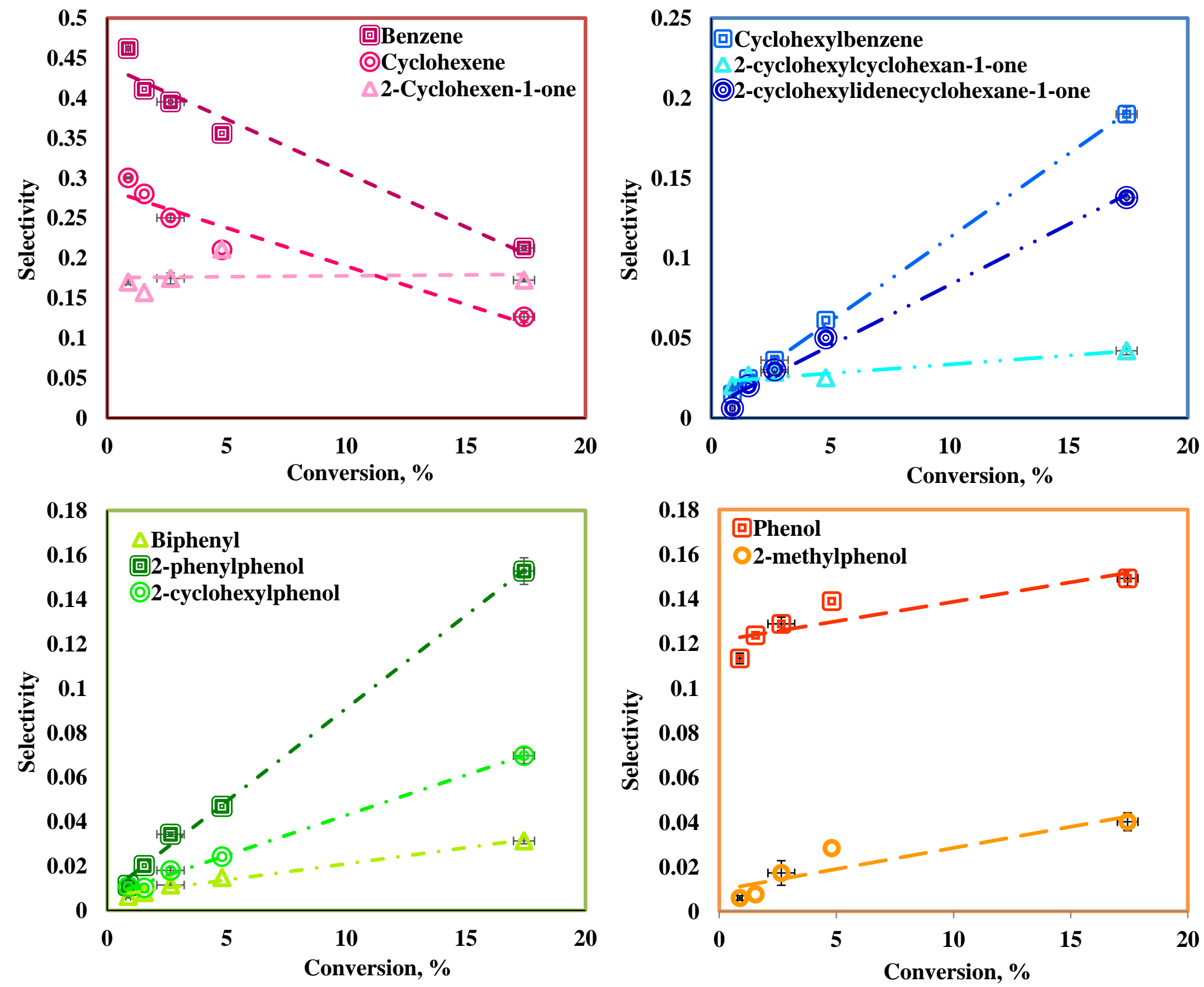

Figure 2-c 




Figure 3 



Figure 4-a 

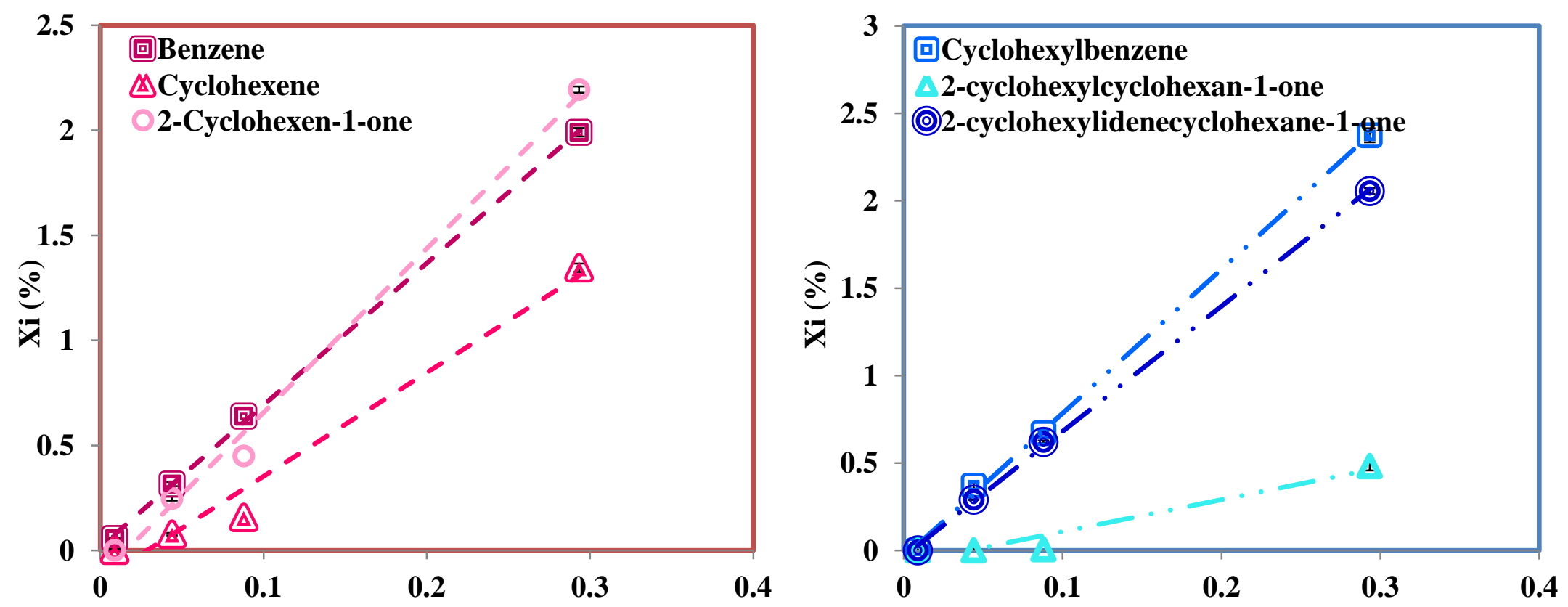

Inverse $\mathrm{WHSV},(\mathrm{g}$ of catalyst $\times \mathrm{h}) /(\mathrm{g}$ of cyclohexanone $)$
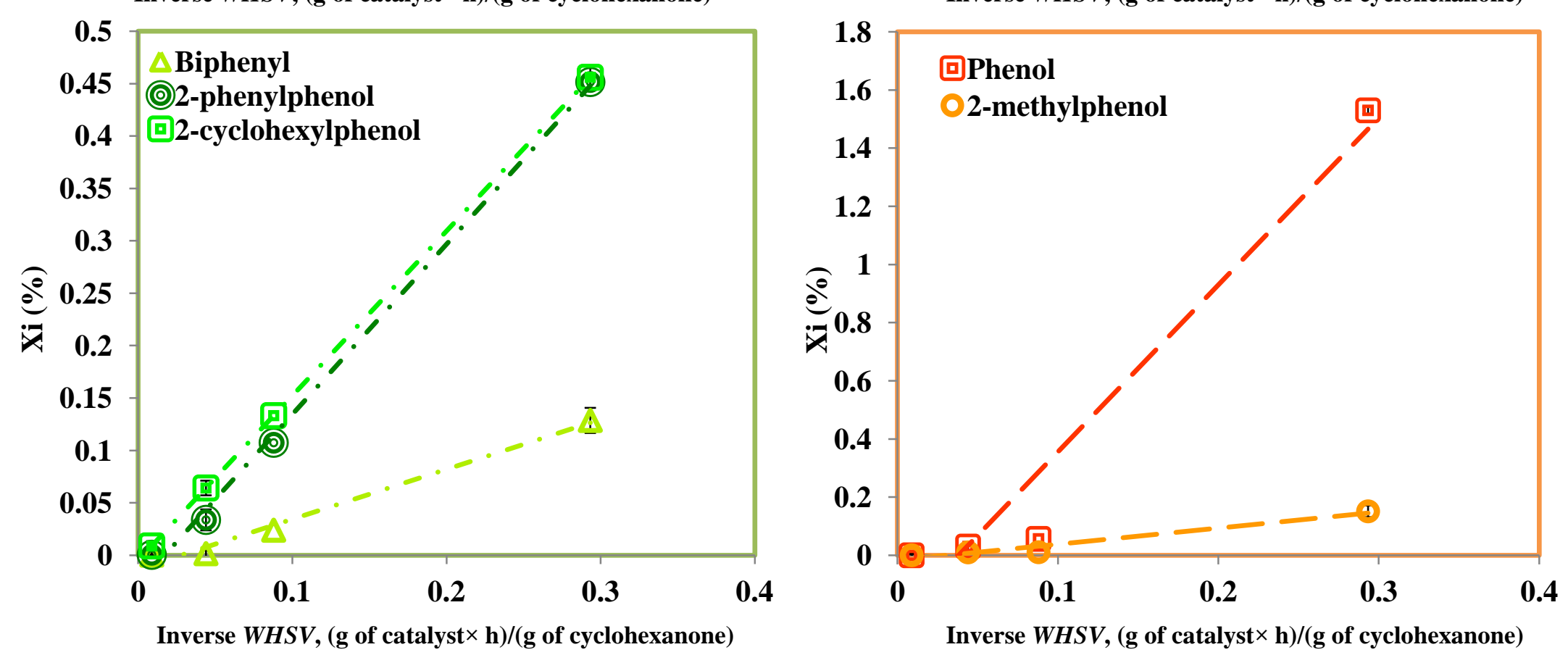

Figure 4-b 

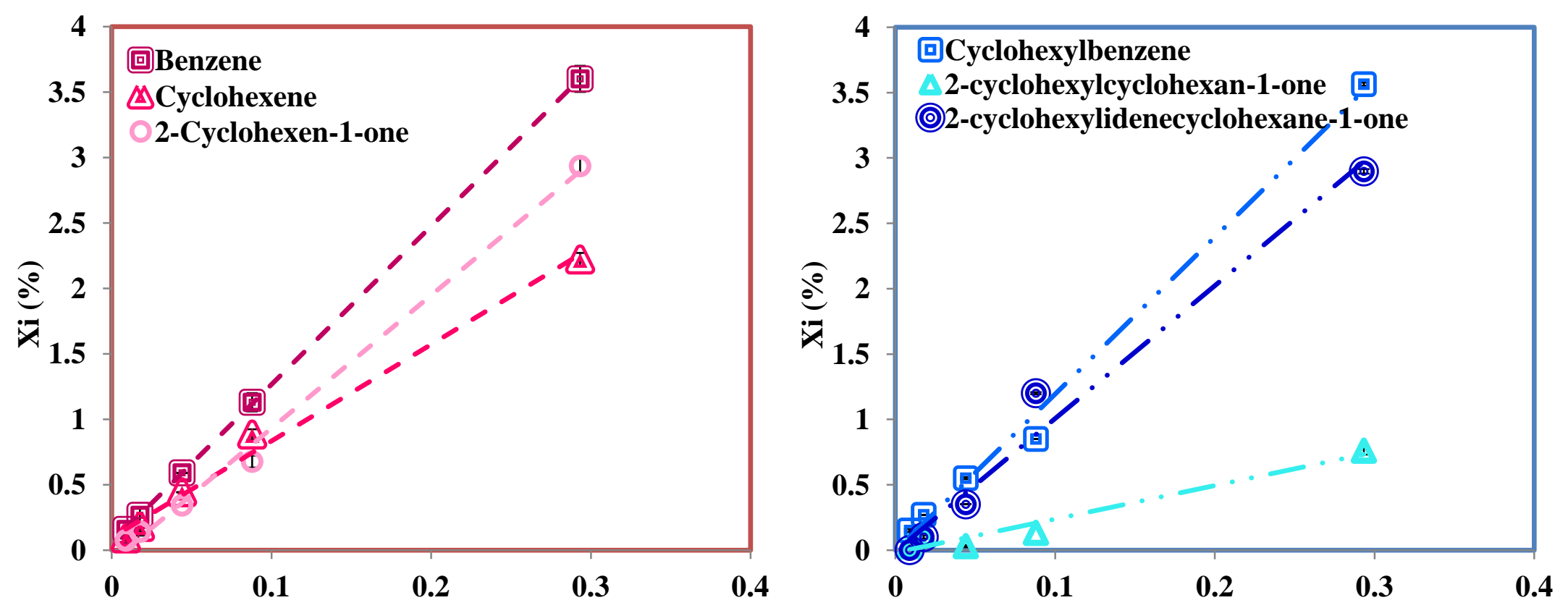

Inverse $W H S V,(g$ of catalyst $\times h) /(g$ of cyclohexanone $)$


Figure 4-c 

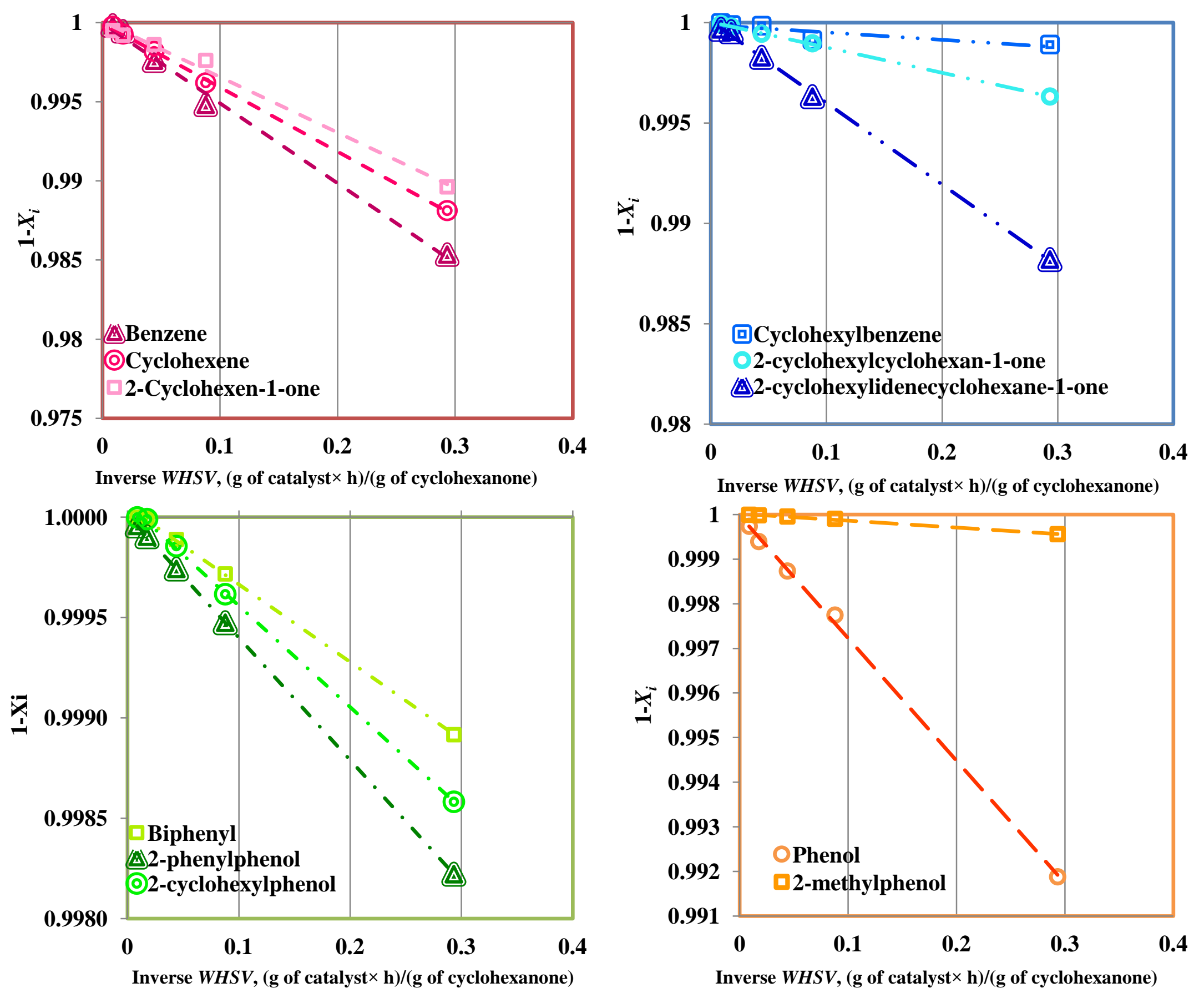

Figure 5-a 


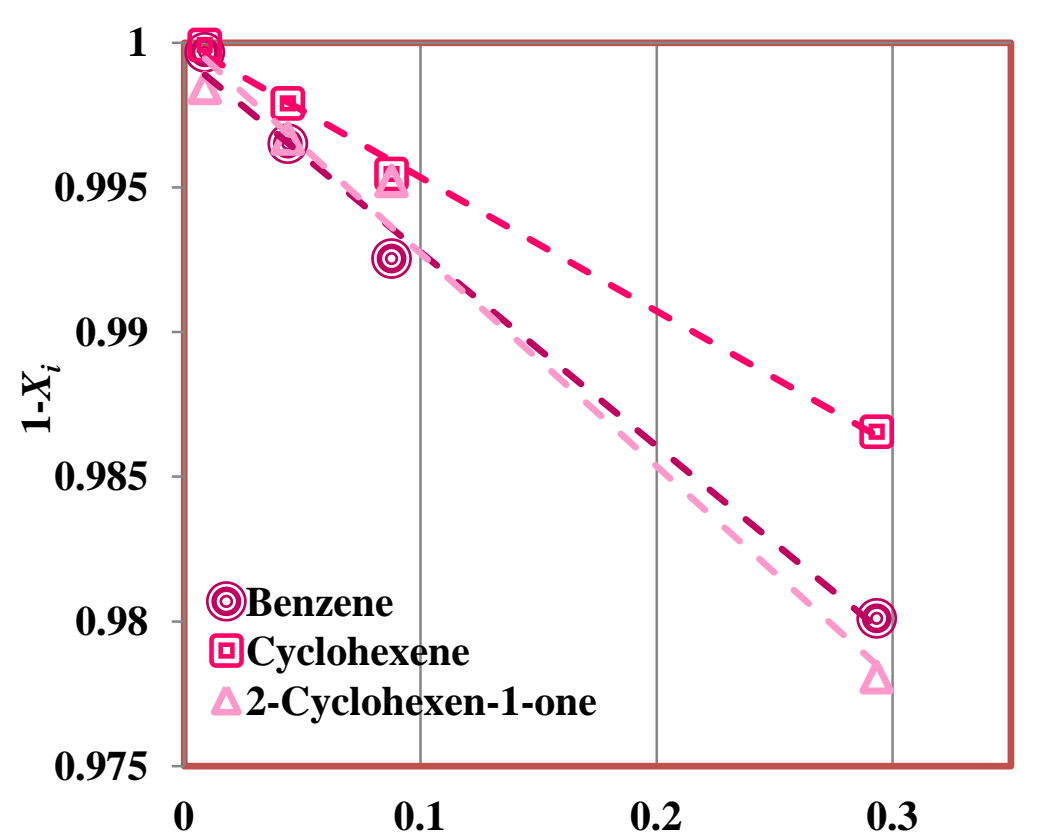

Inverse $W H S V,(\mathrm{~g}$ of catalyst $\times \mathrm{h}) /(\mathrm{g}$ of cyclohexanone $)$

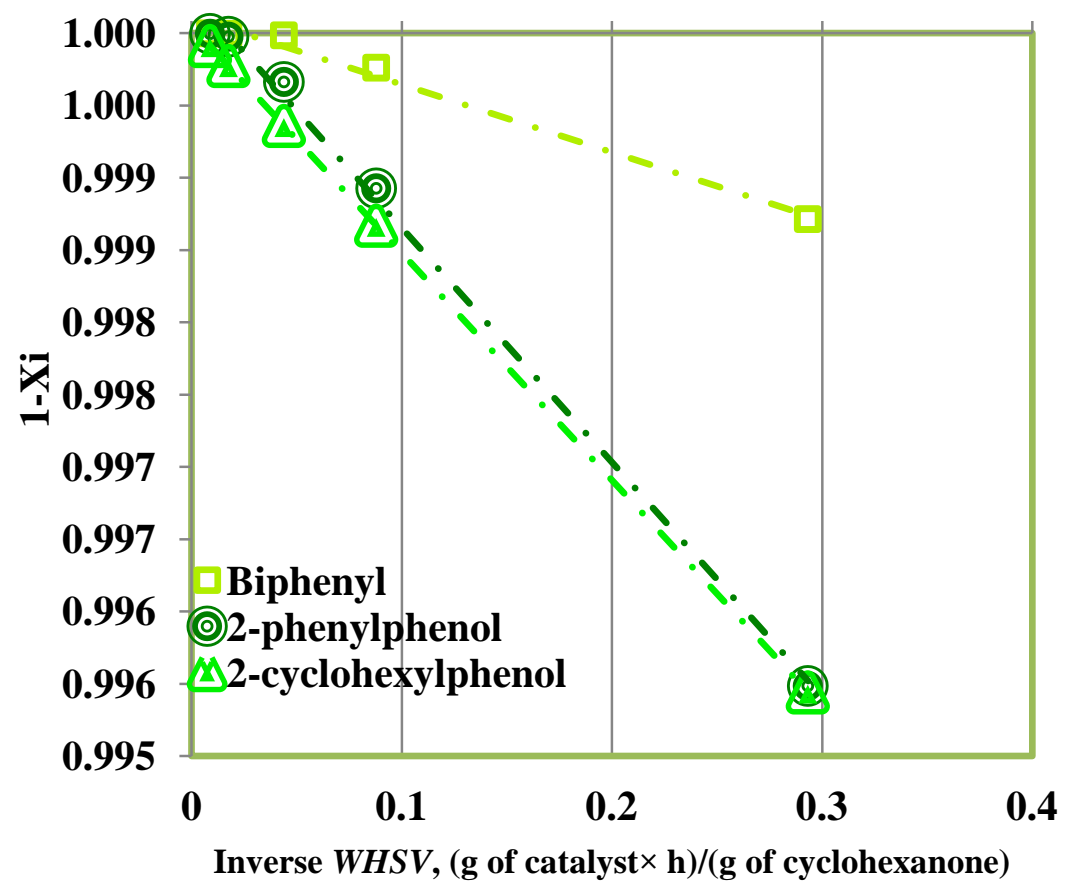

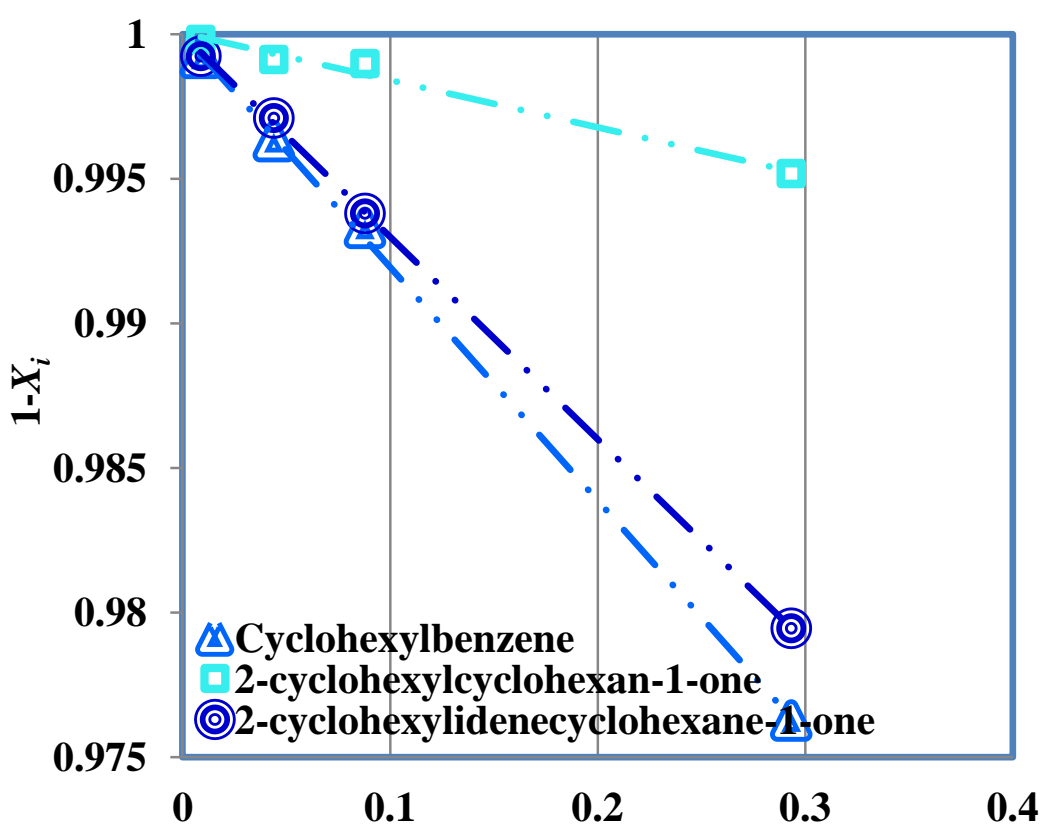

Inverse $W H S V,(g$ of catalyst $\times h) /(g$ of cyclohexanone $)$

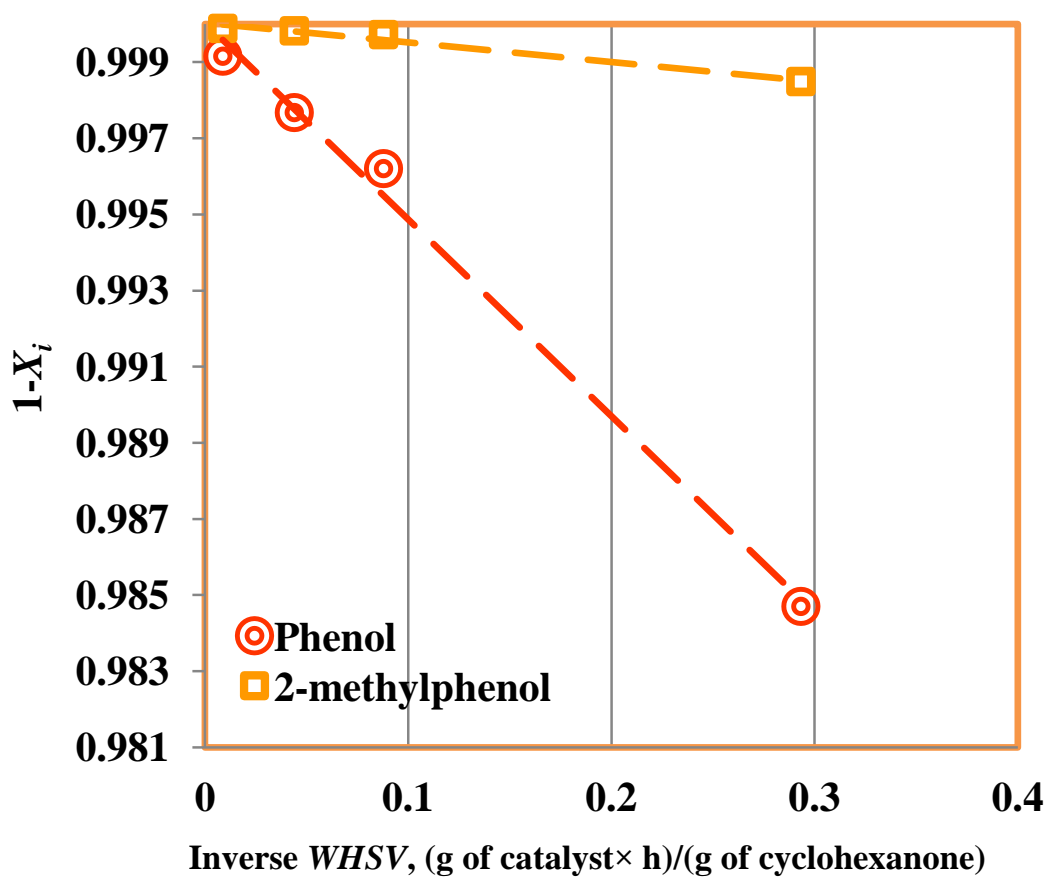

Figure 5-b 

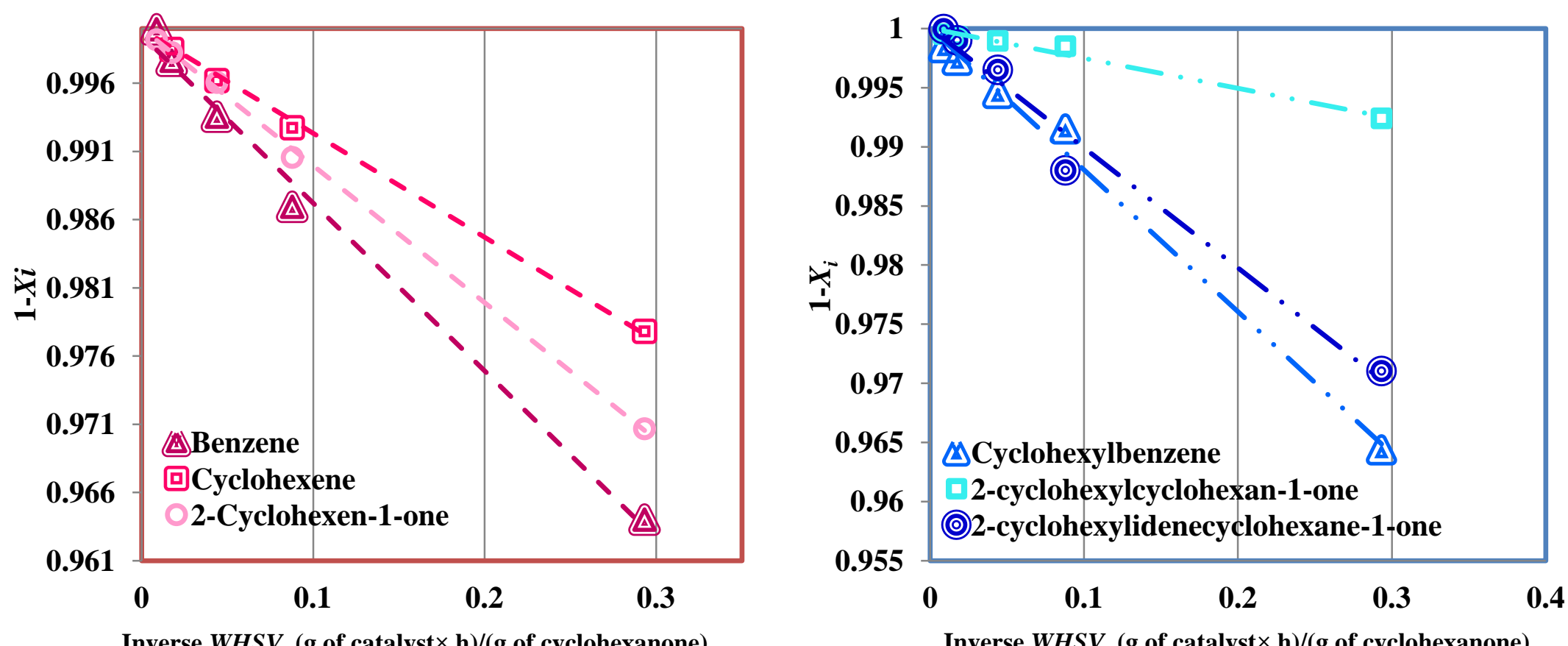

Inverse $\mathrm{WHSV},(\mathrm{g}$ of catalyst $\times \mathrm{h}) /(\mathrm{g}$ of cyclohexanone $)$


Inverse $\mathrm{WHSV},(\mathrm{g}$ of catalyst $\times \mathrm{h}) /(\mathrm{g}$ of cyclohexanone $)$

Figure 5-c 




Figure 6-a 


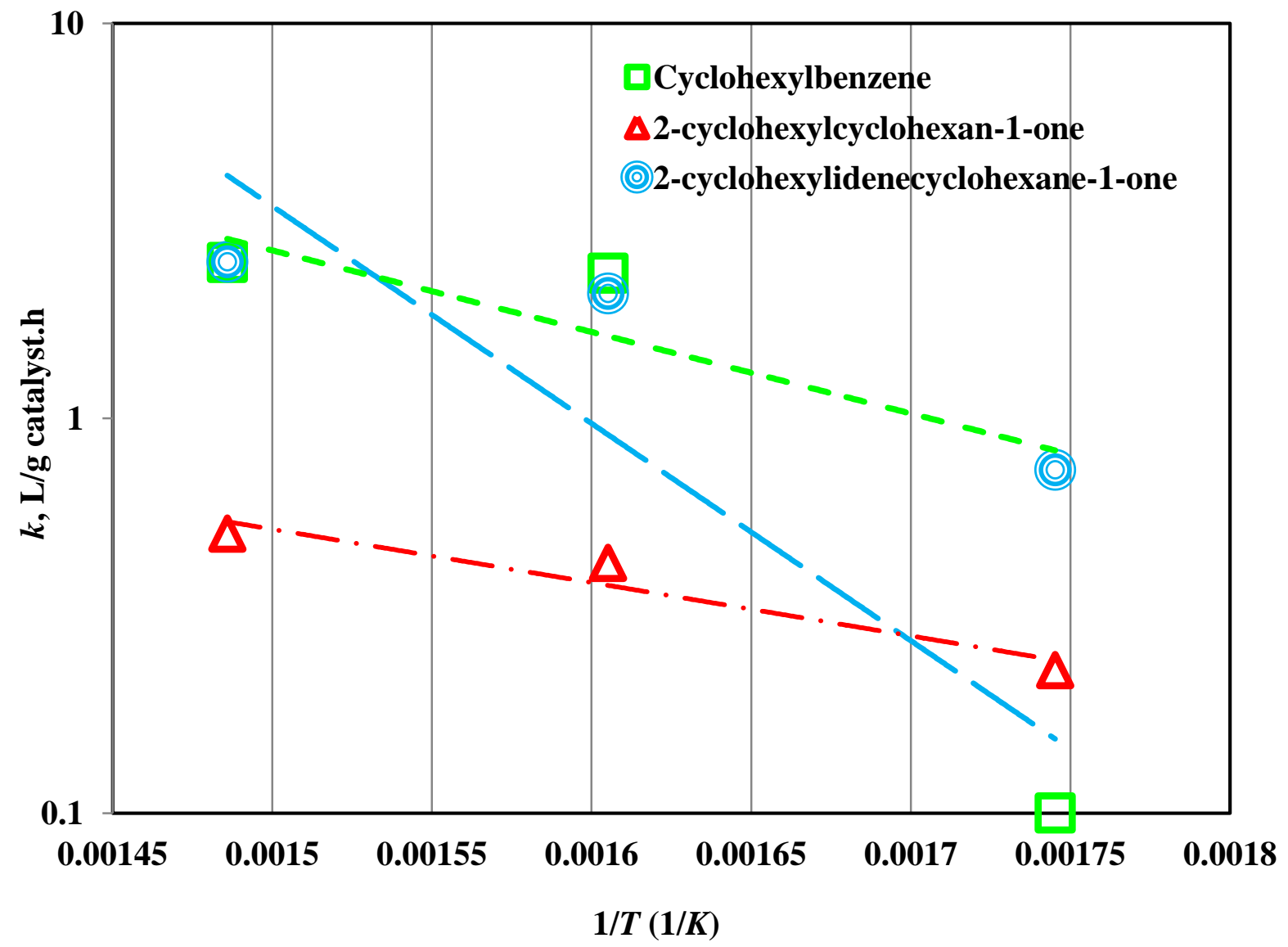

Figure 6-b 


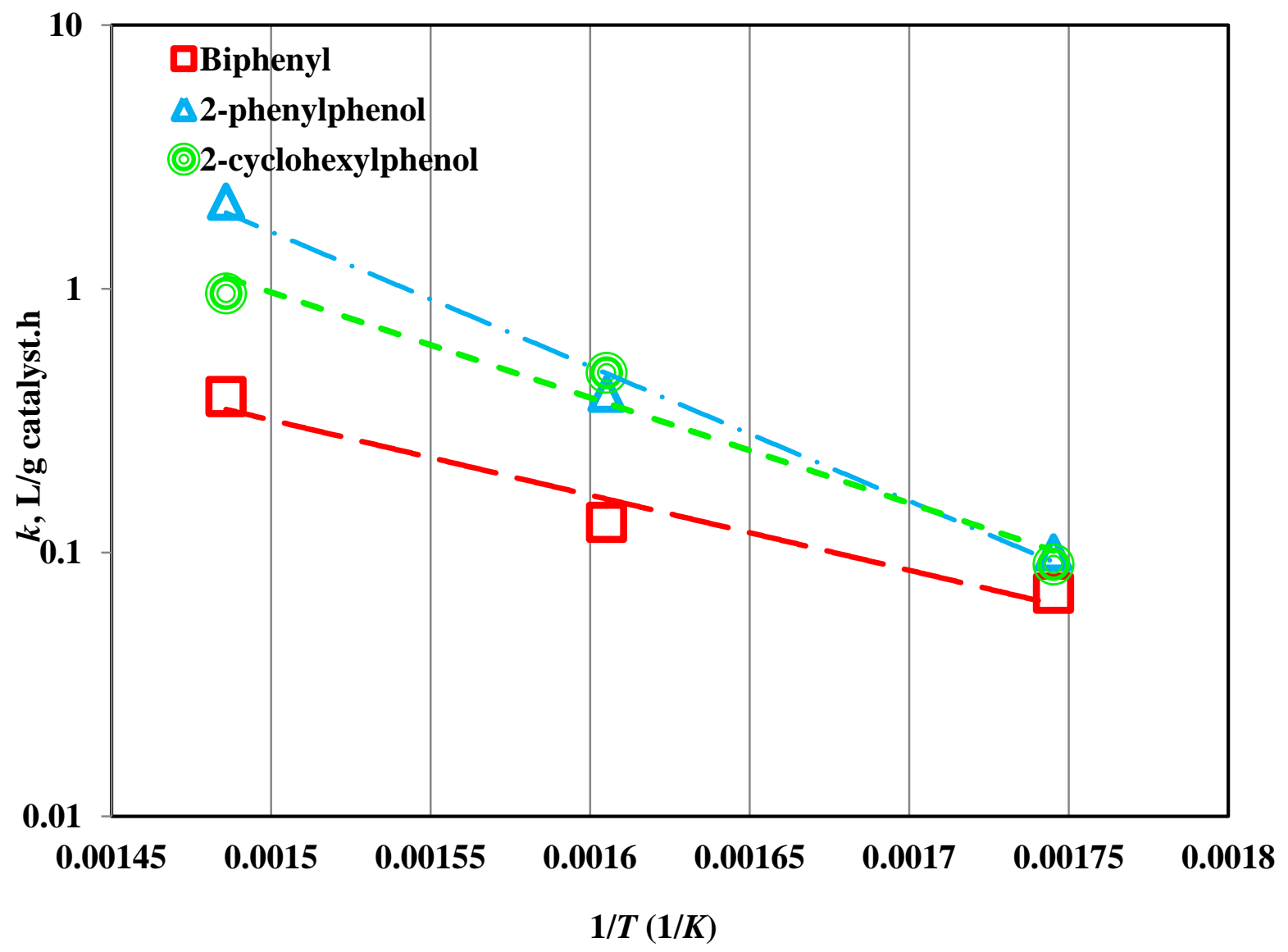

Figure 6-c 


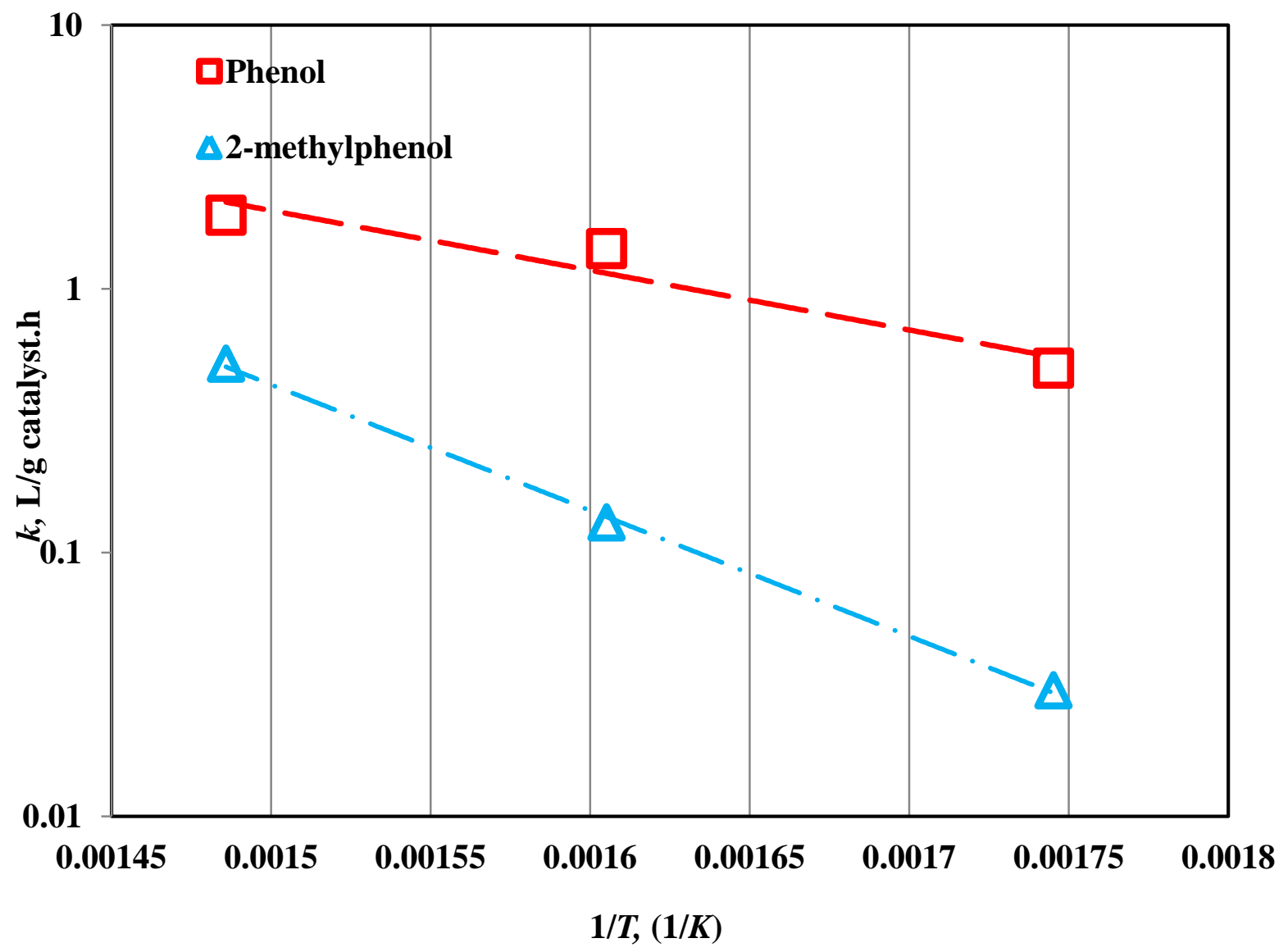

Figure 6-d 




Figure 7 




Figure 8 


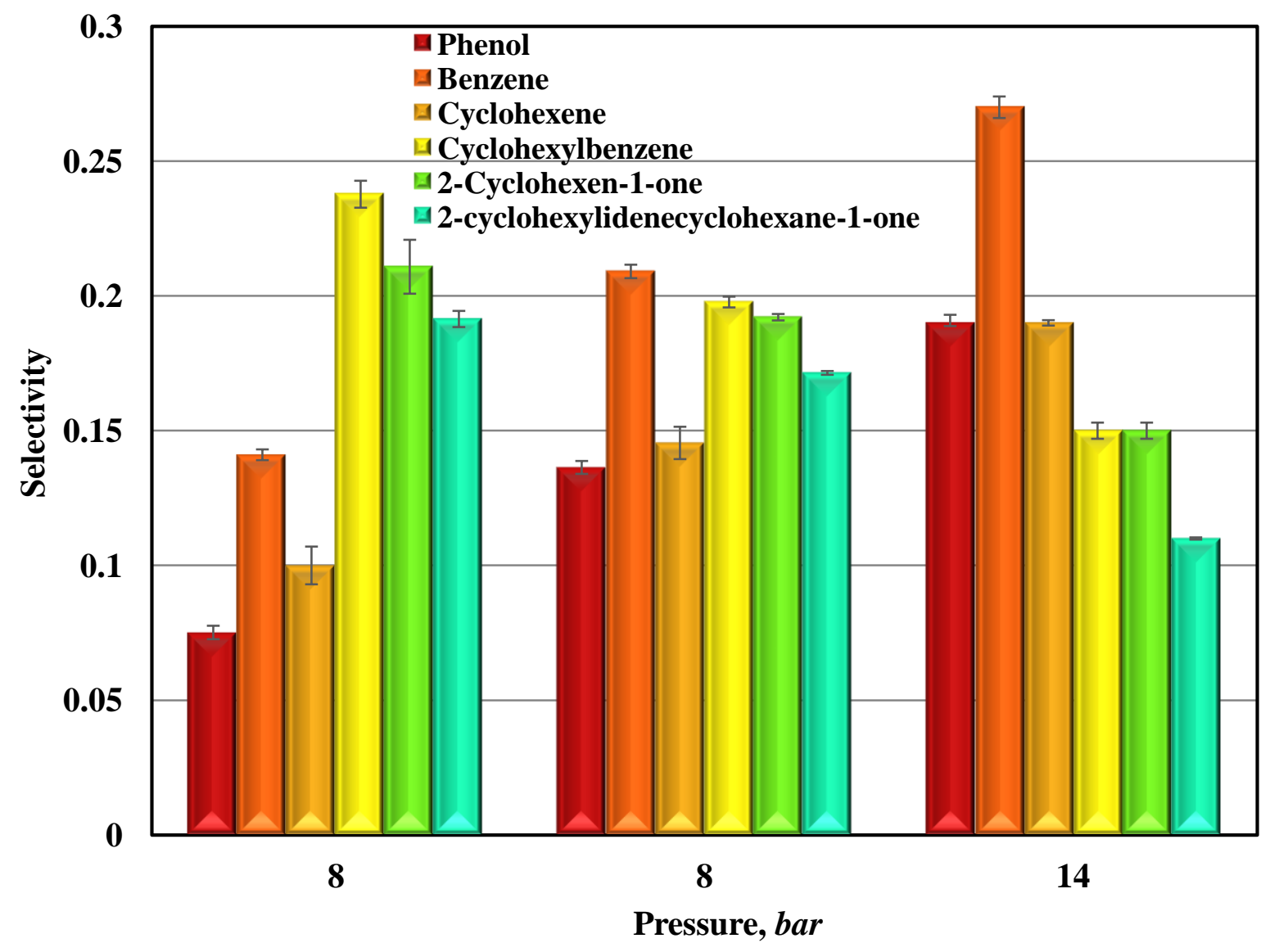

Figure 9-a 


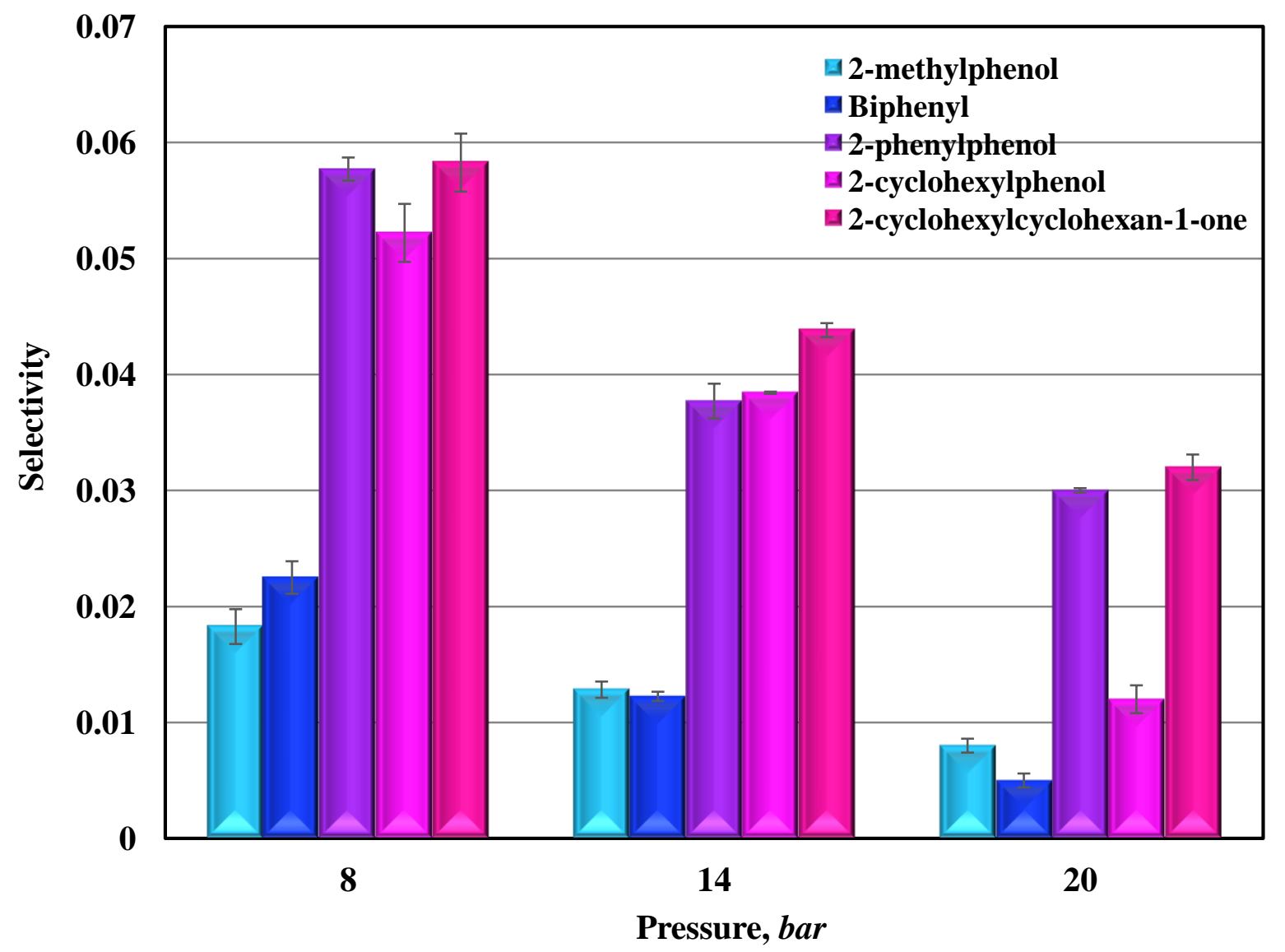

Figure 9-b 